\title{
La indefensión y la inmotivación como causa de nulidad del laudo arbitral en el derecho venezolano*
}

\section{María Candelaria Domínguez Guillén**}

Resumen: se reflexiona sobre la indefensión como causa de nulidad del laudo arbitral en el derecho venezolano y en otros ordenamientos jurídicos. También se analiza la "inmotivación" como causa de nulidad del laudo arbitral, pues si bien la ley venezolana parece matizar dicho requisito con la intervención de la voluntad de las partes, se concluye que la motivación del laudo arbitral es de orden público incluso en decisiones de equidad como manifestación del debido proceso, del derecho a la defensa y en aras de la paz social.

Palabras clave: arbitraje, laudo arbitral, indefensión, inmotivación, derecho a la defensa, debido proceso y orden público.

\section{The Defencelessness and Inmotivation as Causes of Invalidity of the Arbitration Award in the Venezuelan Law}

Aвstract: This article tackles on the defencelessness as a cause of invalidity of the arbitration award in the Venezuelan law and other legal systems. Also,

Fecha de recepción: 29 de febrero de 20I6. Fecha de aceptación: 9 de octubre de 2016.

Para citar el artículo: M. C. Domínguez Guillén, "La indefensión y la inmotivación como causa de nulidad del laudo arbitral en el derecho venezolano", Revista de Derecho Privado, Universidad Externado de Colombia, n. ${ }^{\circ}$ 3I, julio-diciembre de 2016, 229-262. Dor: http://dx.doi. org/IO.1860I/or $234366 . n 3$ I.08

Investigación presentada en el V Congreso de Derecho Procesal Constitucional y III Congreso de Derecho Administrativo, Caracas, Universidad Monteávila, 23 de octubre de 2015.

** Abogada. Especialista en Derecho Procesal. Doctora en Ciencias, Mención "Derecho". Profesora titular. Investigadora-docente, Instituto de Derecho Privado de la Universidad Central de Venezuela, Caracas, Venezuela. Contacto: mariacandela I970@gmail.com 
the "immotivation" is analyzed as a cause of invalidity of the arbitration award. Although Venezuelan law seems to clarify the requirement with the intervention of party autonomy, it is concluded that the motivation of the arbitration award is part of the public policy, including decisions of equity as a manifestation of due process, of the right to defense and for the sake of social peace.

KEYwords: Arbitration, arbitration award, defencelessness, immotivation, right to defense, due process and public police.

Sumario: Introducción. i. La nulidad del laudo arbitral. A. Noción y fundamento del arbitraje. B. Impugnación del laudo arbitral. II. La indefensión como causa de nulidad del laudo arbitral. A. Necesidad de preservar el derecho de defensa en el proceso arbitral. B. La indefensión y la nulidad del laudo arbitral. III. La motivación como proyección del derecho de la defensa en la decisión arbitral. A. Necesidad de motivación del laudo arbitral. B. La inmotivación como causa de nulidad del laudo arbitral. A manera de conclusión. Bibliografía.

\section{Introducción}

Con las breves líneas que siguen reflexionaremos sobre la indefensión como causa de nulidad del laudo arbitral en el ordenamiento jurídico. Omitiremos pues al examen global de la nulidad del laudo arbitral.

Hemos dividido las siguientes líneas en tres ítems: el primero, a título introductorio, se refiere a la nulidad del laudo arbitral; el segundo desarrolla el punto central de nuestra reflexión, a saber, la indefensión como causa específica de nulidad del laudo arbitral; finalmente, el tercer y último aspecto, como derivado de lo anterior, hace una consideración sobre la necesidad de motivación del laudo arbitral, y de allí la referencia a la "inmotivación" ', a la par de la indefensión que da título a este trabajo. Al efecto, hacemos uso de la doctrina venezolana especial y eventualmente extranjera sobre la materia, así como a alguna referencia jurisprudencial.

I De allí que utilicemos la expresión “inmotivación”, equivalente a omitir los motivos de hecho y de derecho que llevan al árbitro a fundamentar o razonar su decisión. 


\section{La nulidad del laudo arbitral ${ }^{2}$}

\section{A. Noción y fundamento del arbitraje}

El arbitraje se presenta como un sistema o modo alternativo de solución de $\operatorname{conflictos}^{3}$ que surge del acuerdo de las partes, sistema que permite que estas

2 Véase Rodner, J. O., "La anulación del laudo arbitral”, en Estudios de derecho procesal civil. Libro Homenaje a Humberto Cuenca, Colección Libros Homenaje n. ${ }^{\circ}$ 6, Caracas, Tribunal Supremo de Justicia, 2002, 82 I-88I ; Mezgravis, A., "Recursos contra el laudo arbitral comercial”, en La Ley de Arbitraje Comercial, Caracas, Biblioteca de la Academia de Ciencias Políticas y Sociales, Serie Eventos I3, I999, pp. 205-272; Aveledo Morasso, L. E., "El recurso de nulidad en el arbitraje civil y comercial", Revista de la Fundación Procuraduría General de la República n. 2 I, año I 3, I999, 249-262; González Arteaga, J., "Recursos interponibles contra el laudo arbitral a la luz de la ley de arbitraje comercial", Revista Venezolana de Estudios de Derecho Procesal n. ${ }^{\circ}$ I, Instituto Venezolano de Estudios de Derecho Procesal, Invedepro, Livrosca, enero-junio I999, I39-2 I 5 (especialmente la nulidad en pp. I66-202); Hung Vaillant, F., "Principios orientadores del arbitraje en la ley de arbitraje comercial y los recursos contra el laudo arbitral", en ххи fornadas 7. М. Domínguez Escovar, Los medios alternativos de resolución de conflictos, 3 a 7 de enero de $200 \mathrm{I}$, Instituto de Estudios Jurídicos del Estado Lara, Colegio de Abogados del Estado Lara, Barquisimeto, 200 I, Iо I-I 56; Díaz-Candia, H., El correcto funcionamiento expansivo del arbitraje (Teoría general del arbitraje), $2 .^{a}$ ed., Caracas, Legis, 20ı3, I76-ı86; Díaz-Candia, H., "La conciliación y el arbitraje comercial en el contexto de la reciente jurisprudencia del Tribunal Supremo de Justicia de la República Bolivariana de Venezuela", en Memoria Arbitral, coord. C. Milagros Betancourt, Caracas, Centro Empresarial de Conciliación y Arbitraje (CEdca), 20 I I, I87-I89; Gabaldón, F., Análisis a la Ley de Arbitraje Comercial, Caracas, Livrosca, I999, I 29-1 53; Henríquez La Roche, R., El arbitraje comercial en Venezuela, Caracas, Centro de Arbitraje de la Cámara de Comercio de Caracas, 200o, 289-299; Sarmiento Sosa, C. J., Ley de Arbitraje Comercial, Caracas, Livrosca, I999, 83-95; MogoLlón Rojas, I. D., El arbitraje comercial venezolano, Caracas, Vadell Hermanos, 2004, pp. I I 8-i 24; Badell Madrid, R. et al., Comentarios a la Ley de Arbitraje Comercial, Caracas, Cuadernos Jurídicos Badell \& Grau, I998, 45-50; Delgado Soto, G., "Nulidad de la cláusula arbitral", en Arbitraje comercial interno e internacional. Reflexiones teóricas y experiencias prácticas, Caracas, Academia de Ciencias Políticas y Sociales y Comité Venezolano de Arbitraje, Serie Eventos I8, Caracas, 2005, coord. Irene de Valera, 236 y 237; AsapchI, M., Arbitraje comercial: impugnación y ejecución del laudo arbitral, Caracas, Universidad Católica Andrés Bello, Dirección General de Estudios de Postgrado, Especialización en Derecho Mercantil, 2007, disponible en: http://w2.ucab.edu.ve/tesis-digitalizadas2/ths_grade/especializacion-de-derecho-mercantil.html; Álvarez Alberto, T., Procesos civiles especiales contenciosos, 4 . $^{\text {a }}$ ed., Caracas, Universidad Católica Andrés Bello, 201 2, t. I, $257-289$; Monroy Cabra, M. G., "Recursos contra el laudo arbitral", en El contrato de arbitraje, Eduardo Silva Romero (dir. académico) y Fabricio Mantilla Espinosa (coord. académico), Bogotá, Legis y Universidad del Rosario, 2005, 67I-682; Martín Brañas, C., "La acción de anulación frente a laudos arbitrales: especial referencia a su tramitación procedimental”, en Foro, nueva época, 3, 2006, I I 3-I 56, disponible en: https://revistas.ucm.es/index.php/Foro/article/download/.../I 3649 ; Ortiz Herbener, A., "Acción de nulidad de laudos arbitrales en el derecho procesal ecuatoriano", Revista furídica, Universidad Católica de Guayaquil, disponible en: www.revistajuridicaonline.com Criollo Mayorga, G., Problemas de la "acción" de nulidad del laudo arbitral, disponible en: http:// www.cejamericas.org; Reggiardo, Mario, Las causales de anulación del laudo en el Perú, disponible en: http://lexarbitri.pe/wp-content/uploads/20 I4/o3/Las-causales-de-anulaci\% $\mathrm{C}_{3} \% \mathrm{~B}_{3}$ n-de-laudoI 5.2.I4-Mario-Reggiardo.pdf; Remón, J., La anulación del laudo: el pacto de exclusión y el orden público, disponible en: http://www.uria.com/documentos/publicaciones/I9oo/documento/o6rlaudoUM. pdf?id= $=94^{2}$

3 Herrera Mercado, H., "El arbitraje en el derecho privado", en Los contratos en el Derecho Privado. Fabricio Mantilla y Francisco Ternera (dirs. académicos), Bogotá, Legis y Universidad del 
diriman sus divergencias sin necesidad de acudir a los órganos jurisdiccionales del Estado. De allí que para algunos es una manifestación de la "justicia privada”, pues se trata de una forma escogida autónomamente por las partes con el fin de resolver conflictos 4 . Mediante el arbitraje, las partes sustituyen la jurisdicción que tienen los tribunales de la República5. Tal escogencia puede tener lugar mediante cláusula compromisoria (establecida previamente en el contrato) o acuerdo arbitral (posterior al conflicto) ${ }^{6}$. Aunque se indica que tal distinción ha perdido relevancia dado el artículo 5 de la Ley de Arbitraje Comercial7.Cabe recordar que de conformidad con el artículo 6 eiusdem en los contratos de adhesión, dada su naturaleza, se precisa acuerdo arbitral por separado ${ }^{8}$.

Rosario, 2008, p. 665: el arbitraje constituye un mecanismo de justicia alternativa al proceso judicial.

4 Díaz-Candia, ob. cit., p. i i. Véase también Petsold-Rodríguez, M., "Algunas consideraciones sobre el arbitraje en general", en Derecho y Sociedad n. ${ }^{\circ}$ 4, 2003, Revista de estudiantes de Derecho de la Universidad Monteávila, pp. 28 y 29, disponible en: http://www.ulpiano.org.ve/revistas/bases/ artic/texto/DERYso/4/deryso_2003_4_27-40.pdf; PeTsold-Rodríguez, M., "Algunas consideraciones sobre el acuerdo arbitral en la Ley de arbitraje comercial, y la cláusula arbitral y el compromiso arbitral en el Código de Procedimiento Civil de Venezuela", en Estudios de Derecho Procesal Civil. Libro Homenaje a Humberto Cuenca, Colección Libros Homenaje n. ${ }^{\circ}$ 6, Caracas, Tribunal Supremo de Justicia, 2002, p. 644; Martínez Manotas, P., Algunas consideraciones sobre la cláusula arbitral desde la legislación colombiana y mexicana, tesis para obtener el grado de maestro en Derecho de los negocios internacionales, Universidad Iberoamericana, México, 2007, vir y I, disponible en: http://www.bib.uia.mx/tesis/pdf/or 4847/or 4847.pdf; Vidal Ramírez, F., 'Jurisdiccionalidad del arbitraje", en Revista Peruana de Arbitraje 3, Grijley, 2006, p. 54, disponible en: http://www.peruarbitraje.org/pdf/revista/REvISTA_PERUANA_DE_ARBITRAJE_RPA_3_2006.pdf; Mejía Arnal, L. A., "El arbitraje: visión histórica y de Derecho Comparado", Revista Venezolana de Estudios de Derecho Procesal n. ${ }^{\circ}$ I , Instituto Venezolano de Estudios de Derecho Procesal, INvEDEPRo, Livrosca, enero-junio, I999, p. 7; durante siglos en los albores de la historia, los hombres resolvieron sus controversias sin recurrir al poder de un Estado que no existía como tal.

5 Juzgado Superior Segundo en lo Civil, Mercantil, Bancario, del Tránsito y de Protección de Niños, Niñas y Adolescentes de la Circunscripción Judicial del Estado Carabobo, Sentencia Iо-8-го, exp. I2.618, disponible en: http://carabobo.tsj.gob.ve/decisiones/2010/agosto/732-IO-I 2.61 8-.html

6 Petsold-Rodríguez, Algunas consideraciones sobre el arbitraje en general, cit., p. 29; Oppetit, B., Teoría del arbitraje, Bogotá, Legis, 2006, 2 I 9 y 220, SAGHY, P., "La convención de arbitraje: por el avance de la justicia estatal frente al arbitraje comercial", en Revista de la Facultad de Ciencias Furídicas y Politicas n. ${ }^{\circ}$ I 29, Universidad Central de Venezuela, 2007, 2 I 4; Martínez Manotas, ob. cit., p. I4; B. de Maekelt, T. y Madrid, C., "Al rescate del arbitraje en Venezuela", en $E l$ derecho privado y procesal en Venezuela. Homenaje a Gustavo Planchart Manrique, Caracas, Universidad Católica Andrés Bello/Tinoco, Travieso, Planchart \& Núñez, Abogados, 2003, t. II, 728; Petsold-Rodríguez, Algunas consideraciones sobre el acuerdo arbitral, 643-666.

7 Caridad de Navarro, M., "Arbitraje comercial: nuevo paradigma para la administración de justicia", Frónesis, vol. I 2, n. ${ }^{\circ}$ 2, Caracas, agosto, 2005, disponible en: http://www.scielo.org.ve/scielo. php?pid=SI $315-62682005000200005$ \&script=sci_arttext; DE Jesús O., A., Validez y eficacia del acuerdo de arbitraje en el derecho venezolano, en Arbitraje comercial interno e internacional. Reflexiones teóricas y experiencias prácticas, coord. Irene de Valera, Caracas, Academia de Ciencias Políticas y Sociales y Comité Venezolano de Arbitraje, Serie Eventos i 8, Caracas, 2005, pp. 59 y 60.

8 Que prevé: "en los contratos de adhesión y en los contratos normalizados, la manifestación de voluntad de someter el contrato a arbitraje deberá hacerse en forma expresa e independiente"; TSJ/spa, Sentencia 672 del Io-6-I 5, disponible en: http://historico.tsj.gob.ve/decisiones/spa/ 
Esta justicia alternativa por voluntad de las partes cuenta con una referencia expresa en el artículo 258 de la Constitución de la República Bolivariana de Venezuela, luego de referirse a la justicia de paz: “... la ley promoverá el arbitraje, la conciliación, la mediación y cualesquiera otros medios alternativos para la solución de conflictos”. Por lo que la figura del arbitraje en Venezuela encuentra proyección constitucional9.

\section{B. Impugnación del laudo arbitral}

La figura del arbitraje es pues producto de la autonomía de la voluntad de las partes que deciden someterse a este, pero como suele acontecer en derecho, tal autonomía no es absoluta, y de ahí que el proceso arbitral deba cumplir con las garantías típicas de la jurisdicción. De allí surge inicialmente la discusión -generalmente rechazada por la doctrina- respecto de que una vez pactado el arbitraje pueda operar una renuncia tácita de este cuando una de las partes demande ante la jurisdicción ordinaria y la otra no oponga tal jurisdicción ${ }^{\mathrm{IO}}$.

En cuanto a las opciones para impugnar el laudo arbitral, la "nulidad" constituye el recurso por antonomasia, dentro de las opciones tradicionales a nivel procesal que orientan la figura, ubicándose entre los recursos excepcionales que pueden intentarse contra el laudo arbitral. El Tribunal Supremo de Justicia venezolano ha considerado excluida la posibilidad de casación ${ }^{\mathrm{II}}$, a diferencia de

junio/I 7836i-00672-io6I 5-20I 5-20I3-0964.HTML; Aarons P., F., "Los medios alternativos de solución de controversias y las transacciones financieras", en Memoria arbitral, coord. C. Milagros Betancourt, Caracas, Centro Empresarial de Conciliación y Arbitraje (CEDCA), 20 I I, I 5-I 7; De Jesús O., ob. cit., roo y ıo ; Maekelt y Madrid, ob. cit., 733.

9 Véase Hernández-Bretón, E., “Arbitraje y Constitución: el arbitraje como derecho fundamental", en Arbitraje comercial interno e internacional. Reflexiones teóricas y experiencias prácticas, coord. Irene de Valera, Caracas, Academia de Ciencias Políticas y Sociales/Comité Venezolano de Arbitraje, Serie Eventos i8, Caracas, 2005, 2 I-34; Hernández-Bretón, E., El arbitraje y las normas constitucionales en Venezuela: lo malo, lo feo y lo bueno, en Boletín de la Academia de Ciencias Políticas y Sociales n. ${ }^{\circ}$ I 49, julio-diciembre, 20 Io, 391-407, disponible en: http://acienpol.msinfo.info/bases/biblo/texto/boletin/20 Io/BolacPs_2Oro_I49_389-407. pdf; Fernández Rozas, J. C., "La Constitución mexicana y el arbitraje comercial”, Cuest. Const. n. ${ }^{\circ}$ I 6, México, ene./jun., 2007, disponible en: http://www.scielo.org.mx/scielo.php?pid=S I40591932007000 I00006\&script=sci_arttext

Io Véase Saghy Cadenas, Pedro J., La renuncia tácita al arbitraje, junio de 2015 , I-2 7, disponible en: http://www.cedca.org.ve/sites/default/files/La\% 2 orenuncia \% 2 ot $\% \mathrm{C}_{3} \%$ A 1 cita $\% 20 a l \% 20$ arbitraje\% 20-Pedro\% 2oSaghy.pdf; De Jesús O., ob. cit., ı०4-ıо9; para el autor no puede ser invocado como en el procedimiento ordinario (ibíd., p. Io9).

I I Véase TsJ/Sala Const., Sentencia I.773 de 30-I I-I I, disponible en: http://historico.tsj.gob.ve/ decisiones/scon/Noviembre/I 773-30 I I I I-20 I I-I I-038 I.html (Caso Van Raalte de Venezuela, C.A), Gaceta Oficial n. ${ }^{\circ}$ 39.84I I2-I-I2; Juzgado Superior Segundo en lo Civil, Mercantil, Tránsito y Bancario de la Circunscripción Judicial del Área Metropolitana de Caracas, Sentencia 26-6-I3, exp. AC7I-R-20II-OOoI46, disponible en: http://jca.tsj.gob.ve/.../20I3/ JUnio/2 I 39-26-AC7 I-R-20 I I-OOo I46-.HTmL; DíaZ-CAndia, El correcto..., cit., I 78. Véase con anterioridad a tales decisioens, Rodner, ob. cit., p. 858; GonZÁlez ArteagA, ob. cit., pp. 202- 
tiempos anteriores ${ }^{\mathrm{I} 2}$. Y como es natural, amén de esta también se excluye la apelación ${ }^{13}$ y la invalidación ${ }^{14}$. Se indica que debe evitarse la multiplicidad de recursos contra el laudo arbitral pues ello puede conducir a la "destrucción de hecho del arbitraje" ${ }^{15}$. Se admite sin embargo que la vía excepcional del amparo ${ }^{16}$ y la revisión constitucional ${ }^{17}$ siguen estando abiertas ${ }^{18}$, según indicó el Tribunal Supremo cuando se pronunció sobre la improcedencia de la casación ${ }^{19}$. Por lo anterior, la posibilidad de impugnación del laudo arbitral es "limitada" dada su naturaleza, siendo esta característica "un dato positivo, que refleja la confianza y

205; Baumeister Toledo, A., "Algunos tópicos sobre el procedimiento en la ley de Arbitraje Comercial", en Arbitraje comercial interno e internacional. Reflexiones teóricas y experiencias prácticas, coord. Irene de Valera, Caracas, Academia de Ciencias Políticas y Sociales y Comité Venezolano de Arbitraje, Serie Eventos I 8, Caracas, 2005, I 45 .

I2 TSJ/scc, Sentencia 586 de 29-II-I I, disponible en: http://historico.tsj.gob.ve/decisiones/scc/ Noviembre/RC.000586-29 I I I-20 I I-I I-307.html; Díaz-Candia, La conciliación..., cit., pp. igo- 196; Zumbiehl, F. y Eloy Anzola, J., El Tribunal Supremo de Venezuela riñe con el Arbitraje, pp. 38 y 39, disponible en: http://eanzola.com/images/uploads/44-El_TSJ_ri\%C3\%Bre_con_ el_arbitraje-Final.pdf; Henríquez La Roche, ob. cit., pp. 299-300.

I3 Mezgravis, ob. cit., p. 2 I9; Hung Vaillant, ob. cit., pp. i 2 I-I23; Rodner, ob. cit., p. 825; GonZález Arteaga, ob. cit., pp. I47-I48 y I 52-I66.

I4 Mezgravis, ob. cit., pp. 2 I9-22 I; GonZález Arteaga, ob. cit., pp. 205-2 I I.

I 5 Gabaldón M., F., Algunas temas en torno a la Ley de Arbitraje Comercial, en Estudios de Derecho Procesal Civil Libro Homenaje a Humberto Cuenca, Colección Libros Homenaje n. ${ }^{\circ}$ 6, Caracas, Tribunal Supremo de Justicia, 2002, 387.

i6 Véase aunque en general es vista con reserva: Mezgravis, A., "El amparo constitucional y el arbitraje", Revista de Derecho Administrativo n. ${ }^{\circ}$ 6, mayo-agosto, I999, pp. 255-278; Mezgravis, Recursos..., cit., pp. 224-24I; Asapchi, ob. cit., pp. 70-73; Hung VaILLANT, ob. cit., pp. I23-I 25; Díaz-Candia, La conciliación..., cit., pp. i96-i98; Rodner, ob. cit., 84i-846; De Jesús O., A., Crónica de Arbitraje Comercial n. ${ }^{\circ}$ 3, Revista de Derecho n. ${ }^{\circ}{ }_{23}$, Tribunal Supremo de Justicia, 2006, I25-I 55; De Jesús O., A., "La Sala Constitucional y el arbitraje comercial. Hacia un régimen racional de control judicial del laudo arbitral en el Derecho Venezolano", Revista Peruana de Arbitraje 3, Grijley, 2006, 64, disponible en: http://www.peruarbitraje.org/pdf/revista/ REVISTA_PERUANA_DE_ARBitraJe_RPA_3_2006.pdf; Zumbiehl y Eloy Anzola, ob. cit., 32-38; Gabaldón, Análisis..., cit., pp. I53-I 55; Henríquez La Roche, ob. cit., 300-309; Baumeister Toledo, ob. cit., pp. I 44 y I45; González Arteaga, ob. cit., 2 i I-2 I 5 ; Petit Guerra, L., "Breves reflexiones sobre sentencias en materia arbitral", Revista Venezolana de Estudios de Derecho Procesal n. ${ }^{\circ}$ I, Instituto Venezolano de Estudios de Derecho Procesal, invedepro, Livrosca, enero-junio, I999, I34; Remón, ob. cit., 7 y 8; тsJ/SConst., Sentencia I 529 de 4-7-02, Jurisprudencia Ramírez y Garay, t. I90, julio, 2002, I00 ss. (también en: www.tsj.gob.ve/decisiones/ scon/Julio/I 529-040702-02-0782\%20.htm); TsJ/SConst., Sentencia 462 del 20-5-10, disponible en: http.//historico.tsj.gob.ve/decisiones/scon/mayo/462-205 IO-2010-1o-oo80.HTML

I 7 Véase BADELL MADRID, R., "El recurso de revisión constitucional en el arbitraje", Revista Comité de Arbitraje 2010-20I I, I-I 7, disponible en: http://www.cedca.org.ve/sites/default/files/Revista $\% 20$ de\% 20Arbitraje\% 202 da\% 20 Edici\% 3 \% B 3n.pdf; тsJ/SConst., Sentencia 2 IO5 de I4-9-04, disponible en: http://historico.tsj.gob.ve/decisiones/scon/Septiembre/2 I05-I40904-03-3170\% 20. htm; Juzgado Superior Segundo en lo Civil, Mercantil, Tránsito y Bancario de la Circunscripción Judicial del Área Metropolitana de Caracas, Sentencia 26-6- I3, exp. AC7 I-R-20 I I-0oo I 46, http:// jca.tsj.gob.ve/DECISIONES/2OI3/JUNIO/2 I 39-26-AC7 I-R-2OI I-OOOI 46-.HTML

i 8 Véase GonZÁlez Arteaga, ob. cit., p. I44.

I9 Véase TsJ/SConst., Sentencia I 773 de 30-I I-I I, disponible en: http://historico.tsj.gob.ve/decisiones/scon/Noviembre/I 773-30 I I I I-20 I I-I I-O38 I.html 
el respecto que las autoridades judiciales mantienen por este mecanismo alternativo de resolución de conflictos" 20 .

De allí que se califique la nulidad del laudo arbitral en esencia como "único recurso"2 ${ }_{21}$ ordinario y se afirme que "la única manera de cuestionar el resultado del arbitraje es través del recurso de nulidad contra el laudo" ${ }^{22}$. Y así puede afirmarse que la anulación es el recurso que se admite, en principio, a tenor del artículo 43 de la Ley de Arbitraje Comercial que indica expresamente: "Contra el laudo arbitral únicamente procede el recurso de nulidad". Se trata de un recurso "excepcional" 23 , pues la ley trata de reducir a su mínima expresión la intervención judicial con relación al laudo arbitral ${ }^{24}$, dado el carácter extraordinario del recurso de nulidad o anulación del equivalente a la sentencia ${ }^{25}$, y la voluntad implícita de las partes de no someterse a los recursos que caracterizan la jurisdicción ordinaria. Se indica, sin embargo, que ello no ha dejado de generar descontento entre algunos abogados acostumbrados al catálogo de recursos judiciales, que se ven limitados por el proceso $\operatorname{arbitral}^{26}$.

$\mathrm{Al}$ efecto, ha indicado la Sala Constitucional: "la pretensión de nulidad de un laudo arbitral se trata de una acción excepcional que solo puede proceder en los supuestos contenidos en el artículo 44 de la Ley de Arbitraje Comercial, orientada a enervar la validez del mismo, ya que su procedencia solo es posible por motivos taxativos, lo que comporta la imposibilidad de afirmar que tal recurso se constituya en una 'apelación' sobre el mérito del fondo" ${ }^{27}$.

Pero en todo caso, se admite que la nulidad del laudo arbitral constituye una manifestación del control judicial propiamente dicho de las decisiones arbitrales. La pretensión de anulación es diseñada por el legislador para que forme parte del conjunto de instrumentos que evitan la total emancipación del sistema arbitral respecto de la jurisdicción, impidiendo con ello que las partes en conflicto puedan verse, una vez aceptada la solución arbitral, definitivamente despojadas de su derecho de acceso a los tribunales. De esta forma, la propia acción se convierte livia, Legis, disponible en: http://www.arbitrajecomercial.com/BancoConocimiento/J/jurispru-
dencia_dr_haderspoock/jurisprudencia_dr_haderspoock.asp?CodSeccion=I 5 En dos ocasiones
se pretendió la declaratoria de inconstitucionalidad en dicho país.

27 TSJ/SConst., Sentencia 462, del 20/05/2010, disponible en: http:/www.tsj.gob.ve/decisiones/ $\mathrm{scon} / \mathrm{mayo} / 462-205$ IO-2010-10-0080.html 
en garante del derecho a la tutela judicial efectiva de los ciudadanos ${ }^{28}$. Las partes acuden al arbitraje gracias a un ejercicio de libertad, pero la misma se garantiza mediante el control judicial del proceso arbitral, por vía del recurso de nulidad ${ }^{29}$.

Entre las características de la nulidad del laudo arbitral se incluye que se trata de un recurso extraordinario, que solo procede por las causales taxativas de ley y que no se puede revisar el aspecto sustancial o de fondo ${ }^{30}$ del litigio porque no se trata de una segunda instancia ${ }^{3 \mathrm{I}}$; solo procede por errores in procedendo y no por errores in iudicando; no puede haber debate probatorio o de interpretación del fondo, y está sujeto a las formalidades legales ${ }^{32}$. No se debe perseguir la corrección de las posibles deficiencias en que pueda incurrir la decisión de los árbitros, ni interferir en el proceso de elaboración de esta última, creando con ello dificultades al móvil de paz que preside la institución arbitral y despojándolo de sus características esenciales de sencillez y confianza en el mismo, pues de esa forma se pretendería un total examen del fondo del asunto que la naturaleza del recurso no consiente ${ }^{33}$.

La Ley de Arbitraje Comercial34 venezolana consagra en el Capítulo vis "De la Anulabilidad del Laudo" en sus artículos $43^{[35]}$ a 47 . La doctrina refiere que

28 Martín Brañas, ob. cit., p. i i 7. Véase en el mismo sentido, Ortiz Herbener, ob. cit., quien siguiendo a Burgos Ladrón de Guevara reseña que la acción de nulidad del laudo arbitral no es otra cosa que el "desembarco jurisdiccional en el arbitraje, de la garantía irrenunciable de la tutela judicial efectiva, garantía jurisdiccional de que el Estado no puede desatenderse totalmente del arbitraje, ya que debe ejercer un cierto control del laudo arbitral, funcionando así, como termómetro necesario en la búsqueda de un equilibrio entre la flexibilidad que rige en el arbitraje y las garantías exigibles en el proceso civil".

29 GonZález Arteaga, ob. cit., p. I 49: "Ese control judicial garante se mecaniza o instrumentaliza a través del recurso de nulidad".

30 Véase Reggiardo, ob. cit., El recurso de anulación no sirve para cuestionar el fondo del conflicto resuelto en el laudo; Asapchi, ob. cit., p. 74: no es para atacar una decisión injusta sino nula; ALva Navarro, E., Arbitraje. La anulación del laudo. Primera Parte. Con la colaboración de Roger Vidal Ramos, Biblioteca de Arbitraje del Estudio Mario Castillo Freyre. Perú, 201 I, p. 22, disponible en: http://www.castillofreyre.com/archivos/pdfs/vol I4.pdf; El arbitraje en el ojo del buracán, busca su evolución dentro del contexto jurídico, I5 de junio de 2015, http://www.lawyerpress.com/CIMA/ CIMA_I 506_I5_OOI.html: "la acción de anulación está limitada a infracciones formales del laudo pero nunca el juez puede entrar en el fondo del asunto y modificar la opinión del árbitro".

3 I Véase Remón, ob. cit., p. 5 .

32 Véase Monroy Cabra, ob. cit., p. 673: los laudos arbitrales que, por regla general, sean susceptibles de anulación por errores de procedimiento -in procedendo-, y no por errores de tipo sustancial -in judicando-".

33 Martín Brañas, ob. cit., pp. I 20 y I 2 I.

34 Gaceta Oficial n. ${ }^{\circ} 36.430$ de 7 de abril de 1998.

35 Dicha norma consagra expresamente su carácter excepcional al señalar: "Contra el laudo arbitral únicamente procede el recurso de nulidad. Este deberá interponerse por escrito ante el Tribunal Superior competente del lugar donde se hubiere dictado, dentro de los cinco (5) días hábiles siguientes a la notificación del laudo o de la providencia que lo corrija, aclare o complemente. El expediente sustanciado por el tribunal arbitral deberá acompañar al recurso interpuesto. La interposición del recurso de nulidad no suspende la ejecución de lo dispuesto en el laudo arbitral a menos que, a solicitud del recurrente, el Tribunal Superior así lo ordene 
dicha ley no aplica a los arbitrajes "ordinarios" no comerciales ${ }^{36}$. Las causales de nulidad del laudo arbitral como recurso excepcional están previstas en el artículo 44 ibídem que dispone:

La nulidad del laudo dictado por el tribunal arbitral se podrá declarar:

a. Cuando la parte contra la cual se invoca demuestre que una de las partes estaba afectada por alguna incapacidad al momento de celebrarse el acuerdo de arbitraje;

b. Cuando la parte contra la cual se invoca el laudo no hubiere sido debidamente notificada de la designación de un árbitro o de las actuaciones arbitrales que así lo ameriten, o no ha podido por cualquier razón hacer valer sus derechos;

c. Cuando la composición del tribunal arbitral o el procedimiento arbitral no se ha ajustado a esta Ley;

d. Cuando el laudo se refiera a una controversia no prevista en el acuerdo de arbitraje, o contiene decisiones que exceden del acuerdo mismo;

e. Cuando la parte contra la cual se invoca el laudo demuestre que el mismo no es aún vinculante para las partes o ha sido anulado o suspendido con anterioridad, de acuerdo a lo convenido por las partes para el proceso arbitral;

f. Cuando el tribunal ante el cual se plantea la nulidad del laudo compruebe que según la Ley, el objeto de la controversia no es susceptible de arbitraje o que la materia sobre la cual versa es contraria al orden público.

La referencia a las citadas causales, que han sido consideradas como taxativas dado el carácter excepcional de la nulidad del laudo arbitral ${ }^{37}$, no exime de los problemas de interpretación relativos a cuáles aspectos o vicios procesales podrían subsumirse en las referidas causales del citado artículo 44. Mal podría

previa constitución por el recurrente de una caución que garantice la ejecución del laudo y los perjuicios eventuales en el caso [de] que el recurso fuere rechazado". Obsérvese que el ejercicio del recurso de nulidad del laudo no tiene efecto suspensivo, salvo que se constituya garantía. Podría añadirse que no tiene tampoco efecto "devolutivo" propio de la apelación, sino más bien, limitado en cuanto al trámite procedimental, y a las garantías inherentes al debido proceso. Véase sobre la sustanciación y los efectos del recurso de nulidad del laudo: Rodner, ob. cit., pp. 846-858; González ArteAgA, ob. cit., pp. I99-20r. Véase sobre la posibilidad de nulidad parcial: ibíd., p. 857; GonzÁlez Arteaga, ob. cit., p. I97: la nulidad total o parcial del laudo depende de la causal alegada. Si es total habrá que reponer la causa; si es parcial puede, sin reponer la causa, dejar sin efecto algunos de sus dispositivos. Los dispositivos que subsistan tendrán carácter de cosa juzgada pues se trata de una nulidad no radical.

36 Véase Baumeister Toledo, A., "Algunas consideraciones sobre el procedimiento arbitral en la nueva Ley de Arbitraje Comercial”, Revista Venezolana de Estudios de Derecho Procesal n. ${ }^{\circ}$ I, Instituto Venezolano de Estudios de Derecho Procesal, Invedepro, Livrosca, enero-junio, I999, 24, que continuarán bajo la forma del arbitramento del Código de Procedimiento Civil. Véase especialmente; ibíd., 26-29. A su vez, la LAC (arts. 2 y I I) distingue entre arbitraje "institucional" y arbitraje "independiente" (ibíd., p. 3 I).

37 Véase sobre dichas causales: Mezgravis, Recursos..., cit., 24I-2 50; Hung Vaillant, ob. cit., pp. I3 I-I 33; Díaz-Candia, El correcto..., cit., i80 y i 8 I; Díaz-Candia, La conciliación..., cit., p. I87: las causales deben considerarse taxativas y excepcionales; Rodner, ob. cit., 859-88 I; GonZÁLEZ Arteaga, ob. cit., I69-I9I. 
pretenderse una enumeración a su vez taxativa de supuestos que por su naturaleza será producto de la interpretación ${ }^{3}$. La taxatividad de las causales no elimina pues la amplitud de los supuestos que en ellas se incluyen o subsumen.

Si bien la doctrina se ha planteado la posibilidad de renuncia anticipada a la acción de anulación ${ }^{39}$, creemos que la autonomía de la voluntad no puede suprimir el único medio jurisdiccional de control del laudo $4^{\circ}$. De allí su carácter irrenunciable ${ }^{\mathrm{I}}$, pues el derecho de recurrir no entra en el patrimonio de la parte litigante sino una vez dictado el laudo ${ }^{42}$. De tal suerte que así como no se puede renunciar anticipadamente a la prescripción, sino cuando está consumada43, acontece lo mismo respecto del recurso de nulidad del laudo. La acción de nulidad del laudo arbitral es parte de la tutela judicial efectiva, y por ende de orden público. Por lo que mal puede ser renunciable ab initio el único medio procesal ordinario que consagra la ley respecto de la decisión arbitral que sustituye la sentencia.

En efecto, la autonomía de la voluntad tiene límites en el diseño del proceso arbitral que vienen dados por aquellos requisitos que son inherentes a la función jurisdiccional del estado y que por ende aseguran el derecho a la defensa de las partes y aseguran la verificación del debido proceso 44 .

\section{La indefensión como causa de nulidad del laudo arbitral}

\section{A. Necesidad de preservar el derecho de defensa en el proceso arbitral}

Si bien el arbitraje es un medio alternativo de administración de justicia, más precisamente de justicia privada, el mismo debe derivarse de la voluntad de las partes por ser producto de la clara autonomía de la voluntad de quienes deciden

38 Véase Domínguez Guillén, M. C., Ensayos sobre capacidad y otros temas de derecho civil, 3. ${ }^{\mathrm{a}}$ ed., Caracas, Tribunal Supremo de Justicia, Colección Nuevos Autores n. ${ }^{\circ}$ I, 2010, 748 y 749, en particular la referencia a Emilio Betti que indica: "Solo una especie de mezquindad y de angustia mental dependiente de la falta de educación jurídica explican el asombro del profano en derecho ante una interpretación jurídica, y la pregunta: ¿¿dónde está escrito?”.

39 Véase Rodner, ob. cit., 838 y 839; Remón, ob. cit., 9.

40 Véase Díaz-Candia, El correcto..., cit., p. i 79; Madrid Martínez, C., "El rol del orden público en el arbitraje comercial internacional", Revista de la Facultad de Ciencias furídicas y Políticas n. ${ }^{\circ}$ I 26, Universidad Central de Venezuela, 2006, 83: el poder de juzgar un litigio determinado deriva de la ley y de la voluntad de las partes, aunque la voluntad encuentra como límite el orden público.

4I Véase González Arteaga, ob. cit., p. i67: pues mediante el recurso, el Estado ejerce el control de la actividad arbitral. Véase sobre la irrenunciabilidad del recurso de nulidad: ibíd., i68 y i69.

42 Ibíd., I69.

43 Véase art. I954 c.c.

44 González Arteaga, ob. cit., p. I46; Mejía Arnal, ob. cit., p. 7. Las herramientas son básicamente dos: una de control, para asegurar el debido proceso legal dentro del arbitraje, y otra de libertad, para la determinación por las partes del desarrollo del proceso arbitral. 
someterse a su ámbito, porque el propio ordenamiento jurídico así lo permite. Igualmente, no obstante la flexibilidad que se predica respecto del procedimiento arbitral, el mismo debe contar con las garantías procesales necesarias para garantizar el derecho a la defensa y el debido proceso de quienes deciden acudir a tal figura sustitutiva de la jurisdicción ordinaria, por expreso mandato constitucional aplicable incluso al arbitraje dado que se trata de una cláusula intrínseca a todo Estado de derecho. Por lo que los principios procesales de orden público no ceden ante el proceso arbitral45. De allí que el artículo 44 de la Ley de Arbitraje Comercial consagra las causales por las cuales el laudo arbitral puede excepcionalmente ser objeto de nulidad.

"El arbitraje como cualquier otro medio alternativo para la solución de conflictos, debe ceñirse al respeto de las garantías constitucionales contenidas en los artículos 26 y 49 del Texto Constitucional"46. La institución arbitral se ha mostrado siempre como una alternativa a la jurisdicción, más rápida y menos costosa, para dar solución a los diferentes conflictos de intereses suscitados entre los ciudadanos 47 . Sin embargo, se admite que efectivamente los árbitros ejercen función jurisdiccional $4^{8}$, por lo que su actividad no escapa de la observancia al derecho a la defensa y debido proceso consagrado en el artículo 49 constitucio-

45 Véase Caridad de Navarro, ob. cit, disponible en: http://www.scielo.org.ve/scielo.php?pid=S I 3 I 562682005000200005\&script=sci_arttext: "la base primordial del nacimiento de la institución arbitral está en la voluntad de las partes, igualmente se considera, que todo lo relacionado con 'las normas procedimiento' es materia de orden público"; Baumeister Toledo, Algunas consideraciones..., pp. 34 y 35: se debe mantener el respeto por los derechos y garantías constitucionales del proceso implícitos en el texto de la ley, incluyendo el derechos a la defensa.

46 TsJ/SConst., Sentencia I 328 del I6-Io- I 4, disponible en: http://historico.tsj.gob.ve/decisiones/ scon/octubre/I 70039-I328-I6IOI4-20I4-I4-OI 75-HTML

47 Martín Brañas, ob. cit., I I4.

48 Véase Rengel-Romberg, A., Naturaleza jurisdiccional del laudo arbitral, en Arbitraje comercial interno e internacional. Reflexiones teóricas y experiencias prácticas, coord. Irene de Valera, Caracas, Academia de Ciencias Políticas y Sociales y Comité Venezolano de Arbitraje, Serie Eventos i8, Caracas, 2005, I 77-i 89; González Carvajal, J. I., "Reflexiones sobre las tendencias jurisprudenciales sobre conflicto de "jurisdicción" cuando existe acuerdo de sometimiento arbitral", Revista Venezolana de Legislación y furisprudencia n. ${ }^{\circ}$ 4, 20 I4, 3 I 6, disponible en: http://www.rvlj. com.ve; Mantellini GonzÁlez, P. J., "El arbitramento y el arbitraje comercial”, Boletín de la Academia de Ciencias Politicas y Sociales n. ${ }^{\circ}$ 42, I 986, I 77, disponible en: http://acienpol.msinfo. info/bases/biblo/texto/boletin/I986/BolacPs_I986_42_I05_IO6_I73-I93.pdf: el arbitraje es de naturaleza jurisdiccional; Anzola, J. E., "El fatigoso camino que transita el arbitraje", en Arbitraje comercial interno e internacional. Reflexiones teóricas y experiencias prácticas, coord. Irene de Valera, Caracas, Academia de Ciencias Políticas y Sociales y Comité Venezolano de Arbitraje, Serie Eventos i 8, Caracas, 2005, 428; Hung Vaillant, F., "Apostillas a cinco sentencias en materia arbitral dictadas por el Tribunal Supremo de Justicia", en El derecho privado y procesal en Venezuela. Homenaje a Gustavo Planchart Manrique, Caracas, Universidad Católica Andrés Bello/Tinoco, Travieso, Planchart \& Núñez, Abogados, 2003, t. II, 657: es una forma de jurisdicción no estatal; Baumeister Toledo, Algunas consideraciones..., cit., p. 23. Véase también tsJ/ SConst., Sentencia 462 del 20-5-10, disponible en: http://historico.tsj.gob.ve/decisiones/scon/ mayo/462-205 I0-2010-10-0080.HTML 
nal49. Los instrumentos internacionales también, como es natural, consagran la máxima garantía procesal, a saber, el derecho a la defensa. El apego a la Constitución por parte del laudo arbitral es consecuencia necesaria del respeto al orden jurídico, en el que la Constitución es norma rectora de toda actuación e interpretación. La Constitución se convierte en fuente de normas en materia de arbitraje, que si bien no solucionan de manera directa los problemas arbitrales son portadores de los valores que inspiran ${ }^{50}$. Toda disposición normativa en materia de arbitraje ha de ser interpretada conforme a la Constitución ${ }^{5}$. Así, se ha sostenido inclusive, muy fundadamente, que existe competencia arbitral para resolver una cuestión de constitucionalidad o inconstitucionalidad $5^{2}$.

Los árbitros han de tener como norte de su función la norma del artículo I 5 del Código de Procedimiento Civil venezolano, en cuanto deben garantizar el derecho de defensa y mantener a las partes en sus derechos y facultades comunes y en las privativas de cada una, sin que puedan permitirse ni permitir extralimitaciones de ningún género. Pero con independencia de toda permisión o restricción legal53, una vez planteada la contienda arbitral, "habrá sustanciación de la misma en pos de la salvaguarda del derecho de defensa" 54.

\section{B. La indefensión y la nulidad del laudo arbitral}

El recurso de nulidad está limitado a las causales de ley55. La doctrina, a propósito de la nulidad del laudo arbitral, aclara que este no ha de tener un sentido semejante a la apelación y recomienda que los jueces que conocen de la nulidad del laudo arbitral "sean moderados, condescendientes y jurídicamente corteses con el criterio y discernimiento de los laudos arbitrales" ${ }^{56}$. Pero ello ciertamente ha de tener lugar en el contexto de las causales de ley.

Véase Benaín Izaguri, S., "Reflexiones sobre las posibilidades probatorias de los Centros de Arbitraje", Revista Venezolana de Estudios de Derecho Procesal n. ${ }^{\circ}$ I, Instituto Venezolano de Estudios de Derecho Procesal, Invedepro, Livrosca, enero-junio I999, p. 90: todo procedimiento que se lleve a cabo en nuestro país, aun el arbitral, supone el respeto a las garantías procesales constitucionales de defensa e igualdad. La falta de una referencia expresa en la LAC no es óbice para llegar a una conclusión distinta. Véase ibíd., p. 91: no habrá impedimento para el ejercicio de amparo constitucional cuando el Reglamento del Centro de Arbitraje lesione tales garantías.

Hernández-Bretón, Arbitraje y Constitución, cit., p. 25.

5 I Ibíd., p. 3 I.

52 Sacristán, E. B., "Control constitucional en el Arbitraje”, Revista Bresileira de Infraestrutura RBINF, año 3, n. ${ }^{\circ}$, 2014 , Fórum, 4I y 52.

53 Bonnemaison W., J. L., Sobre la naturaleza y el objeto del arbitraje, disponible en: http://servicio. bc.uc.edu.ve/derecho/revista/57/57-20.pdf

54 SACRISTÁN, ob. cit., p. 45.

55 Rodner, ob. cit., p. 826.

56 Díaz-Candia, El correcto..., cit., p. i 86. 
Las causales de nulidad del laudo arbitral, a pesar de ser taxativas, son lo suficientemente amplias para que en ellas se pueda subsumir cualquier eventual violación de derechos o garantías fundamentales ${ }^{57}$.

Es cierto que el juez que conoce de la nulidad del laudo arbitral no ha de entrar a conocer si este es justo o no, si acontecieron errores in iudicando o si hubo infracción en la valoración de las pruebas ${ }^{5}$. No obstante, se admite que con base en la causal segunda del artículo 44 de la Ley de Arbitraje Comercial, relativa a la imposibilidad de la parte que recurre contra el laudo de hacer valer sus derechos, se incluyen dentro de los supuestos de nulidad aquellas infracciones que se han producido en violación al debido proceso o en menoscabo del derecho a la defensa ${ }^{59}$. Por lo que las transgresiones que parecieran dar lugar a la nulidad del laudo arbitral son aquellas asociadas a los "errores in procedendo" cedimiento en materia de casación. La autonomía del arbitraje no es absoluta. Las cortes judiciales pueden determinar si el procedimiento se ha desarrollado de manera regular o irregular. La revisión judicial de los laudos arbitrales, así entendida, no está llamada a corregir los errores de fondo en que haya incurrido el tribunal arbitral, sino, únicamente, los errores de procedimiento asociados a las garantías procesales fundamentales de las partes ${ }^{6 \mathrm{I}}$.

Señala la doctrina que dicha causal relativa a la imposibilidad de hacer valer los derechos tiene que ver con infracciones del proceso arbitral, y es de tal amplitud que ciertamente no se trata de situaciones de negligencia de las partes, sino de indefensión dentro del proceso civil que procede cuando el juez impide, cercena o menoscaba el derecho a la defensa de una de las partes. Ello ocurriría cuando esto lo hubiere realizado cualquiera de los árbitros ${ }^{62}$.

Por lo anterior suelen constituir causas de nulidad del laudo arbitral las deficiencias que puedan haber impactado en el ejercicio del derecho a la defensa de alguna de las partes o que hayan roto el equilibrio que debe mantenerse entre las partes en conflicto ${ }^{63}$. De allí que entre los motivos de anulación del laudo se ubique como es natural a las violaciones asociadas al derecho a la defensa ${ }^{64}$.

57 Mezgravis, Recursos..., cit., p. 230.

$5^{8}$ Ibíd., p. 244.

59 Ibíd.

60 Véase TsJ//scs, Sentencia 288 I 6-5-02.http://historico.tsj.gob.ve/decisiones/scs/mayo/RC288I60502-01635.HTM: "por error in iudicando se trata de defender la exacta interpretación de cualquier norma jurídica; en el recurso dado por error in procedendo se trata no de asegurar la ejecución de cualquier precepto procesal".

6 i Talero Rueda, ob. cit., p. 235.

62 Aveledo Morasso, ob. cit., p.259.

63 Araque Benzo, L. A., Manual de arbitraje comercial, Caracas, Jurídica Venezolana y Araque Reyna Sosa Viso \& Asociados, 20 I I, I4I.

64 Fortún, A. y Álvarez-Garcillán, G., La impugnación de los laudos arbitrales, disponible en: http://www.cuatrecasas.com/media_repository/docs/esp/la_impugnacion_de_los_laudos_arbi- 
En tal sentido indicó el Tribunal Supremo, en decisión 462 del 20 de mayo de 20 io, en Sala Constitucional, que desde el punto de vista sustantivo el contenido y la extensión de los supuestos regulados en el artículo 44 de la Ley de Arbitraje Comercial permiten ventilar en el correspondiente juicio de nulidad denuncias vinculadas con la violación del derecho a la defensa y a la tutela judicial efectiva $^{65}$, bien sea por contravención al procedimiento legalmente establecido o bien porque el laudo es contrario a normas de orden público, ya que "los medios alternativos de resolución de conflictos al constituirse en parte del sistema de justicia, no pueden desconocer disposiciones sustantivas especiales de orden público, al igual que no podrían quebrantarse por parte del Poder Judicial" o que,

... en caso que la decisión del correspondiente órgano [arbitral] contraríe el sistema jurídico constitucional interno, la misma sería inejecutable en la República, circunstancia que no debería producirse en la medida que la misma esté fundamentada correctamente en el marco jurídico aplicable para la resolución del correspondiente conflicto, como serían tratados internacionales, leyes o disposiciones contractuales, los cuales en todo caso deberán necesariamente atender a las normas de orden público de cada Estado en los cuales se pretenda ejecutar la decisión (Cfr. Sentencia de esta Sala n. ${ }^{\circ}$ I.541/08) ${ }^{66}$.

En efecto, la Ley de Arbitraje Comercial, entre las referidas causales de su artículo 44, incluye en la letra b) que reza: "Cuando la parte contra la cual se invoca el laudo no hubiere sido debidamente notificada de la designación de un árbitro de las actuaciones arbitrales que así lo ameriten, o no ha podido por cualquier razón hacer valer sus derechos" (resaltado nuestro). En tal supuesto se ha de incluir toda circunstancia que de alguna manera produzca indefensión dentro del proceso arbitral, pues mal podría vulnerarse el derecho a la defensa de quienes acuden a este medio sustitutivo de justicia.

Así resalta la doctrina que el dispositivo de esta causal está obviamente dirigido a tutelar "uno de los patrimonios más valiosos de la actividad jurisdiccional como lo es el derecho a la defensa" ${ }^{67}$. No es sostenible el criterio de que la nulidad del laudo arbitral procede solo ante la existencia de un "error inexcusable",

trales._economist_jurist,_n_I7I_20I3_(junio)_340.pdf La "la impugnación de un laudo tiene como objetivos fundamentales que la jurisdicción ordinaria controle, por un lado, los aspectos formales del laudo, la conformidad del arbitraje con el orden público y los derechos de defensa de las partes".

65 Véase Fernández Rozas, ob. cit.: "no cabe entender que, por el hecho de someter voluntariamente determinada cuestión litigiosa al arbitraje de un tercero, quede menoscabado y padezca el derecho a la tutela judicial efectiva".

66 TsJ/SConst., Sentencia 462 del 20-5-10, disponible en: http://historico.tsj.gob.ve/decisiones/ $\mathrm{scon} / \mathrm{mayo} / 462-205$ IO-2010-IO-0O80.HTML

67 González Arteaga, ob. cit., I 75 (resaltado original). 
pues ello sería reducir sobremanera el sentido ya taxativo y limitado del excepcional recurso de nulidad del laudo arbitral, y las garantías procesales deben ser respetadas también en el procedimiento arbitral, visto que se trata de premisas básicas de todo Estado de derecho y, por tanto, de toda forma de administración de justicia ${ }^{68}$. La celeridad del arbitraje no puede mermar las garantías del debido proceso $^{69}$.

Afirma la doctrina:

Por lo tanto se cree prudente, que dentro de estas modalidades de arbitraje contempladas en la Ley de Arbitraje Comercial, se debe reflexionar con mucha precisión sobre el resguardo de las garantías básicas constitucionales en materia de los procesos, es decir, el debido proceso, la igualdad procesal, el derecho a la defensa, derecho a pruebas, entre otros, sin los cuales se puede considerar, que ellos serían procesos totalmente inexistentes a la luz del ordenamiento constitucional, dando lugar así a la impugnación de esos procesos arbitrales, por vía de algunas de las causales de nulidad establecidas por la legislación arbitral, especialmente las contenidas en el Artículo 44 literales b y c ${ }^{70}$.

Y se agrega que la expresión "no ha podido por cualquier razón hacer valer sus derechos" es tan amplia que se traduce en "indefensión" en el proceso civil7 ${ }^{7}$.

La indefensión, como causa de nulidad del procedimiento arbitral, es admitida, no obstante la tendencia restrictiva de las causales de nulidad del laudo. Se afirma que se vincula con los derechos esenciales relativos al debido proceso, manifestado especialmente a través del derecho a la defensa. Por lo que se admite la revisión del laudo basada en irregularidades procesales en la mayoría de los regímenes de derecho ${ }^{72}$.

68 Véase Hernández Machado, E., La inmutabilidad del proceso arbitral, disponible en: http://eldia. com.do/la-inmutabilidad-del-proceso-arbitral/: "la jurisdicción arbitral se rige por los principios procesales básicos de la jurisdicción judicial tales como el derecho de defensa, la tutela judicial efectiva y el debido proceso. La acción en nulidad es el único mecanismo a través del cual es posible ejercer la fiscalización y vigilancia sobre temas tan sensibles".

69 Véase Mejía Arnal, ob. cit., p. I3: "No se trata sólo de lograr una rápida solución de los conflictos, sino que para la persistencia del sistema que estamos instaurando y, en general de la paz social, es necesario que tal solución sea justa y resulte de un proceso conducido por un árbitro imparcial, en el cual se garantice a las partes la verdadera oportunidad de tener noticia de la iniciación del juicio y las oportunidades de alegación y prueba”.

70 Caridad de Navarro, ob. cit.

7 I Caridad de Navarro, M., Contradicciones e imprecisiones legales de la institución arbitral en Venezue$l a$, Trabajo especial para ascender a la categoría de asociado, Maracaibo, Universidad del Zulia, Facultad de Ciencias Jurídicas y Políticas, junio de 2006, p. I 57, disponible en: http://tesis.luz. edu.ve/tb_acen_inv/tde_busca/arquivo.php?codArquivo=27

72 Parodi, G., "La cláusula arbitral: efectos de la elección de la sede del arbitraje y el control judicial. Hacia un sistema de congruencias", Revista de Derecho de la Universidad de Montevideo n. ${ }^{4}$, año II, 2003, p. 6o, disponible en: http://revistadercho.um.edu.uy 
Y así se ha indicado respecto del derecho español que contiene una causal redactada en términos semejantes a la del derecho venezolano: "que la designación de un árbitro no haya sido debidamente notificada a la parte, o que no hayan sido debidamente notificadas a esta las actuaciones arbitrales o que aquella no ha podido, por cualquier otra razón, hacer valer sus derechos". Si bien se mira, dos son en realidad los submotivos que contiene este motivo anulatorio, y ambos tienen como común denominador sancionar la indefensión que se haya podido causar a quien lo alega. El segundo submotivo, de configuración más abierta o indefinida que el primero, permite que se alegue cualquier actuación que haya impedido el ejercicio de los derechos que las partes tengan en el proceso arbitral"73. En el mismo sentido vale citar el derecho ecuatoriano 74 y el derecho peruano 75 . Pues se afirma acertadamente que "el convenio arbitral no implica renuncia de las partes a su derecho fundamental de tutela judicial" 76 .

Así pues, "[s]e incurre en indefensión cuando por un acto imputable al Juez se priva o limita indebidamente a una de las partes el libre ejercicio de los medios y recursos que la ley pone a su alcance para hacer valer sus derechos o se le conceden derechos o facultades no previstas en la ley"77. De allí que, no obstante la dificultad o la inconsistencia en la determinación de las violaciones del derecho a la defensa ${ }^{78}$, debe admitirse que se trata de una noción vital en el ejercicio de la jurisdicción pública o de la alternativa privada, como es el arbitraje.

Vale indicar que no cabe pretender una prescindencia total del procedimiento arbitral para considerar una violación del derecho a la defensa, pues, amén de que ello constituye una causal diferente que bien pudiera estar conectada, a saber, no seguir el procedimiento arbitral, se trata de precisar todos aquellos supuestos determinantes en la defensa de los justiciables, cuya violación pudo configurar un resultado distinto del laudo arbitral. No existirá entonces una lista precisa o taxativa como las causales de la nulidad, sino que a su vez la indefensión

73 Bermejo Reales, L. F., "La eficacia de las decisiones arbitrales: la impugnación y ejecución de los laudos", Revista furídica de Castilla y León n. ${ }^{\circ}$ 29, enero, 201 3, 5 y 6, disponible en: http:// dialnet.unirioja.es/servlet/articulo? codigo $=4225303$ \&orden (destacado fuera de texto).

74 Véase Ortiz Herbener, ob. cit.; Coronel Jones, C., Arbitraje y procedimiento en Ecuador, disponible en: http://www.latinarbitrationlaw.com/arbitraje-y-procedimiento-en-ecuador/

75 Véase Reggiardo, ob. cit.; Alva Navarro, ob. cit., p. I36.

76 Alva Navarro, ob. cit., p. I 38 (cita a Hinojosa Segovia).

77 Véase TsJ/scc, Sentencia 00229 del 26-5-II, disponible en: http://historico.tsj.gob.ve/decisiones/scc/Mayo/RC.00229-265 I I-20 I I-IO-548.html; тsJ/scc, Sentencia 00209 del I6-5-03, disponible en: http:/historico.tsj.gob.ve/decisiones/scc/Mayo/RC-00209-I60503-0I885.htm; TsJ/scc, dec. 00257 de I9-5-05, disponible en: http://historico.tsj.gob.ve/decisiones/scc/mayo/ RECL-OO2 57-I 90505-OI472.HTM; TSJ/scc, Sentencia I 30 de 3-4-03, disponible en: http://historico.tsj.gob.ve/decisiones/scc/Abril/RC-oor 30-030403-OI 75I.htm; TsJ/scc, dec. 00228 de 30-4o9, disponible en: http://historico.tsj.gob.ve/decisiones/scc/Abril/RcH.002 28-30409-2009-08579.html

78 Véase Hernández Mendible, V., "La inconsistencia argumentativa en el análisis del derecho a la defensa", Revista Tachirense de Derecho n. ${ }^{\circ}$ I 3 , enero-diciembre, 200 I, pp. 99-I I9. 
o la violación del debido proceso vendría dada por la interpretación del lesionado o del juzgador en el caso concreto79. Lo anterior, si el supuesto cabe dentro de lo que se ha entendido por "indefensión" extensible al arbitraje de equidad ${ }^{81}$. Por lo que la pretendida tesis de la interpretación restrictiva ${ }^{82}$ de las causales no puede ser alegada para evitar la subsunción, objetivo natural del proceso de interpretación. A lo que cabría responder que las normas de excepción se interpretan como toda norma y lo que está vedado es la "analogía", mas no la "interpretación extensiva" ${ }^{3}$. Lo cual ha sido aceptado por la jurisprudencia peruana en materia de causales de nulidad taxativas del laudo ${ }^{84}$, en especial por el Tribunal Constitucional ${ }^{85}$.

Se insiste que mal podría mediar una enumeración en algo que por su naturaleza habrá de ser producto de las circunstancias. Será el juez quien sea capaz de visualizar o proyectar si la violación acontecida en el proceso fue o pudo ser determinante en la dispositiva del laudo. Y así por ejemplo la inadmisión injustificada de pruebas, la incorrecta distribución de la carga de la prueba o la inadmisión injustificada de la oposición a las pruebas ciertamente constituyen ejemplos

79 Véase León Feoli, A., Debido proceso como causal de nulidad del laudo arbitral, análisis de precedentes de la sala primera de la corte suprema de justicia, p. 7, disponible en: http://sitios.poder-judicial. go.cr/sala I/Temas\% 20jurisprudenciales/Arbitrajes-debido\% 2oproceso.pdf: "La importancia de los preceptos constitucionales que resguardan el debido proceso, en todo trámite de solución de conflictos, se hace también patente en los arbitrajes [...] No existe una definición del debido proceso. Éste comprende esa serie de garantías constitucionales, cuya aplicación demanda el examen cuidadoso de cada caso concreto, tanto del procedimiento arbitral cuanto del laudo, pues las infracciones pueden acontecer no solo en el desarrollo de íter procesal sino también en la decisión final que se adopte sobre el fondo de la contienda".

80 Véase González Arteaga, ob. cit., i 76: el hecho procesal causante de la indefensión ha de cumplir con las condiciones exigidas por la doctrina para que sea considerado realmente un caso de indefensión.

8 I Ibíd., p. I77.

82 Véase Alva Navarro, ob. cit., p. 66: los alcances que se dieron a la causal de nulidad de laudo regulada en el derecho peruano fluctuaron entre quienes defendían la existencia de una regla de interpretación restrictiva y quienes la dejaban de lado para preferir un principio de interpretación constitucional. Véase, sosteniendo el carácter "restrictivo" de las causales del artículo 49 LAC relativas al reconocimiento del laudo y que el autor reconoce similares a las del artículo 44 (salvo la letra g que se introduce en el artículo 49): Barnola Quintero, J. P.: "Reconocimiento y ejecución del laudo arbitral comercial en Venezuela", Revista Venezolana de Estudios de Derecho Procesal $n .^{\circ}$ I, Instituto Venezolano de Estudios de Derecho Procesal, Invedepro, Livrosca, enero-junio, I 999, I 2 2; TsJ/SConst., Sentencia 2 I05 de I4-9-04, disponible en: http://historico.tsj. gob.ve/decisiones/scon/Septiembre/2 I05-I40904-03-3 I 70\% 20.htm: "derivado de la interpretación restrictiva de las causales taxativas de procedencia del recurso de nulidad consagradas en el artículo 44".

83 Véase Domínguez Guillén, ob. cit., pp. 494-497.

84 Véase Alva Navarro, ob. cit., p. 90.

85 Ibíd., p. 9r: "el Tribunal Constitucional ha sido -se quiera o no- bastante claro en sus decisiones, apostando uniformemente cuando ha tenido la oportunidad de hacerlo, por un mayor $-\mathrm{O}$ más adecuado- control al arbitraje, en favor de una mayor tutela de los derechos procesales de quienes deciden elegir esa vía para resolver sus conflictos". 
de violación del derecho a la defensa ${ }^{86}$, toda vez que es bien sabida la trascendencia que la prueba ejerce en el dispositivo del fallo ${ }^{8} 7$, de lo que no escapa el proceso arbitral ${ }^{88}$. Pero ello es extensible a cualquier acto de este que se traduzca en una violación determinante de la defensa como derecho constitucional.

La doctrina venezolana, al comentar la causal indicada, señala que la expresión relativa a la imposibilidad de hacer valer sus derechos, efectivamente se refiere a razones incontrolables, o no imputables o ajenas a la persona ${ }^{89}$. Pues se ha dicho que es el juzgador, en este caso el árbitro, quien cercena o menoscaba el ejercicio del derecho a la defensa de una de las partes. Se agrega que la referida causal en general pretende anular todo laudo que haya sido dictado en violación del debido proceso ${ }^{9}{ }^{\circ}$. Otros refieren que no toda violación al debido proceso supone una violación del derecho a la defensa ${ }^{9}{ }^{\mathrm{I}}$. Pero en todo caso, pudiera concluirse que las violaciones al debido proceso (no seguir el proceso arbitral también es causa autónoma de nulidad, letra c, art. 44 LAC) pueden configurar adicionalmente una violación del derecho a la defensa porque ciertamente le impiden al justiciable hacer valer sus derechos.

\section{La motivación como proyección del derecho de la defensa en la decisión arbitral}

\section{A. Necesidad de motivación del laudo arbitral}

Un aspecto propio o relativo al derecho a la defensa, del debido proceso e inclusive de la tutela judicial efectiva, es la motivación del laudo arbitral, el cual deberá ofrecer las razones que justifican una dispositiva.

Si bien el deber de motivar el laudo no pareciera universal dada la pretendida celeridad que se le adjudica ${ }^{92}$, con proyección en los $\operatorname{costos}^{92}$, existe consenso desde el punto de vista de la racionalidad, en que toda decisión en sede de

86 Véase Coronel Jones, ob. cit.

87 Véase Bello Tabares, H., "El derecho constitucional a la prueba Judicial", Revista de Derecho n. 30, Tribunal Supremo de Justicia, 2009, 33-96.

88 Véase Petit Guerra, L., El sistema de pruebas en el arbitraje desde la asunción del debido proceso como derecho fundamental, 4 y 5, disponible en: http://www.cedca.org.ve/documentos/Luis-Petit.pdf "con la constitucionalización de la prueba como elemento del debido proceso, operan cambios en la jurisdicción ordinaria que deben trasladarse de igual forma al arbitraje"; Benaín Izaguri, ob. cit., 87-IO2.

89 Véase Mezgravis, Recursos, cit., p. 244.

90 Idem; González Arteaga, ob. cit., p. I 76.

9I Véase Reggiardo, ob. cit. Esta causal también señala que procederá el recurso de anulación cuando una de las partes no haya podido hacer valer sus derechos.

92 Véase ibíd., I 41 2 : "la preocupación de querer reducir la duración y el costo de los pleitos ha llevado recientemente a explorar la posibilidad de dictar fallos sin motivación”. Gómez-PaLAcio, I.: El laudo arbitral no motivado. Vía de solución poco explorada en México, 285 , disponible en: http:// 
administración de justicia y que se manifiesta en una sentencia debe estar debidamente justificada; ello quiere decir, motivada. Esto también alcanza al ámbito del arbitraje, pues se trata de un mecanismo de solución de controversias dentro de la administración de justicia. Ello considerando que la instancia arbitral tiene carácter de jurisdicción, partiendo del concepto de su naturaleza reconocida como tal en la Constitución94.

Algunas leyes imponen la motivación de los laudos de manera obligatoria. Es el caso, por ejemplo, de la ley italiana, belga, holandesa, peruana, brasileña o colombiana. Pero la mayoría admiten la posibilidad de un acuerdo contrario de las partes, empezando por la Ley Modelo sobre Arbitraje Comercial Internacional de la Comisión de Naciones Unidas para el Derecho Mercantil Internacional (CNUDMI, mejor conocida por sus siglas en inglés, UNCITRAL, art. 30.2)95.

El artículo 30 de la Ley de Arbitraje Comercial venezolana dispone: "El laudo del tribunal arbitral deberá ser motivado, a menos que las partes hayan convenido lo contrario, y constará en él la fecha en que haya sido dictado y el lugar del arbitraje". De lo que cabe concluir que la motivación forma parte esencial del laudo. Aunque la disposición deja a salvo que las partes hayan pactado lo contrario; previsión que para algunos es perfectamente compatible con la libertad que caracteriza la naturaliza del arbitraje $\mathrm{e}^{6}$.

Pero la posibilidad excepcional de que las partes releven de la motivación a los árbitros ha sido acertadamente criticada porque impide controlar que la decisión sea ajustada a derecho97. Por lo que cabe dudar de la posibilidad de

www.biblio.juridicas.unam.mx/libros/6/2552/I6.pdf: las instituciones fijarían una tarifa más reducida para los laudos no motivados.

93 Véase Véronique Schlaepfer, A. y Cremades, A.-C., "La motivación de los laudos en arbitraje comercial internacional y en arbitraje de inversión", en Arbitraje internacional, pasado, presente y futuro. Libro Homenaje a Bernardo Cremades e Yves Derains, coords. Carlos Alberto Soto Coaguila y Delia Revoredo Marsano de Mur, Lima, Instituto Peruanos de Arbitraje, 20I3, t. II, I4I2, disponible en: http://www.swlegal.ch/CMSPages/GetFile.aspx? disposition=attachment: "La necesidad de motivar un laudo no es tan universal como parece a primera vista, aunque es cierto que hoy existe una cierta convergencia de la normativa internacional, de las leyes nacionales de arbitraje y de los reglamentos arbitrales para exigir de los árbitros que motiven sus laudos".

94 Véase Guzmán Galindo, J. C., "La falta de motivación del laudo como causal de anulación en la ley de arbitraje peruana", Arbitraje PUCP, 35, disponible en: http://revistas.pucp.edu.pe/index. $\mathrm{php} /$ arbitrajepucp/article/download/.../9800

95 Véronique Schlaepfer y Cremades, ob. cit., I4I 5.

96 Véase Villasmil Vera, Y. C. y Hernández Villalobos, L. L., "Régimen legal del arbitraje comercial independiente en Venezuela", Revista de Derecho n. ${ }^{\circ}$ I4, Caracas, Tribunal Supremo de Justicia, 2004, p. 392; Asapchi, ob. cit., p. 63, "la inmotivación no añade riesgo de injusticia al laudo"; Guzmán GaLIndo, ob. cit., p. 36, estamos ante una norma legal obligatoria, pero no imperativa.

97 Véase Baumeister Toledo, Algunas consideraciones, cit., p. 55: no concebimos cómo los árbitros de derecho puedan sustraerse al deber de motivar sus laudos aun con la anuencia de las partes. La motivación no es sólo un requisito esencial para poder precisar justamente si el pronunciamiento es conforme a derecho sino que pretende lograr la aquiescencia de las partes y del grupo social sobre lo decidido. Nava González, J. G., "El arbitraje comercial y el derecho 
que la autonomía de la voluntad se revierta en perjuicio del derecho a la defensa dado su carácter irrenunciable, amén de la posibilidad de que el laudo no sea reconocido en países donde la exigencia es radical ${ }^{8}$. Criterio lógico, pues si se admite que la motivación es expresión del derecho a la defensa que tiene carácter constitucional, bien podría concluirse que la norma que releva de motivación al laudo por voluntad de las partes presenta vicios de inconstitucionalidad, toda vez que se trata de un derecho irrenunciable que excede la simple voluntad de los justiciables. Se trata de un requisito procesal esencial de orden público que tiende a garantizar la paz social.

Para algunos la posibilidad de inmotivación sólo sería procedente en caso de arbitraje de equidad99, toda vez que el artículo $8^{\left[{ }^{[0 o}\right]}$ de la Ley de Arbitraje Comercial alude a que en el arbitraje de derecho se deben observar las "disposiciones de derecho en la fundamentación de los laudos”, en tanto que en el arbitraje de equidad rige la libertad. Pero a ello acertadamente se objeta que al laudo de equidad también se extiende el deber de motivar ${ }^{\text {IOI }}$, pues es imperativo justificar

fundamental de la tutela judicial efectiva”, Boletín de Investigación y Postgrado, I6. ${ }^{a}$ ed., Universidad Privada Dr. Rafael Belloso Chacín, 762, disponible en: http://www I r.urbe.edu/boletines/ postgrado/? $\mathrm{p}=762$ : "Una norma como la antes citada, ineludiblemente, se debe reputar como contraria al derecho a una sentencia fundada, debido a que las partes no pueden bajo ningún concepto renunciar a la motivación del fallo. Además, la anterior exigencia está ligada al derecho de la tutela judicial efectiva y con el ejercicio del derecho a la defensa, pues, es en la parte motiva donde se establecen aquellos razonamientos jurídicos dirigidos a obtener, respecto a lo decidido, la adhesión de las partes y de la sociedad en general. Permitiendo el control de los confl[i]ctuantes sobre el fallo, específicamente en el caso del laudo arbitral, a través de los recursos de nulidad que se pueden ejercitar ante el Tribunal Superior que corresponda".

98 Véase Barragán Arango, L. A., "El laudo arbitral", en El contrato de arbitraje, Bogotá, Legis y Universidad del Rosario, 2005, Eduardo Silva Romero (dir. académico) y Fabricio Mantilla Espinosa (coord. académico), 660 y 66r: en Colombia, como en otros ordenamientos, "no se concibe una decisión judicial o arbitral carente de motivación". Algunas legislaciones aceptan que el arbitraje de equidad pudiera no estar motivado. Sin embargo, el autor duda que un laudo inmotivado pueda surtir efecto en Colombia u otro país que exija dicha motivación, por tratarse de normas procesales sustanciales y de orden público.

99 Véase ibíd., 66r. Villasmil Vera y Hernández Villalobos, ob. cit., p. 392: la motivación del laudo es requerida en un arbitraje de derecho, pero no en un arbitraje de equidad de conformidad con el artículo 8 LAC (en el mismo sentido obtuvimos opinión de Ramón Alfredo Aguilar Camero, profesor agregado de Derecho Procesal de la Universidad Central de Venezuela y especialista en Derecho Procesal).

Iоo "Los árbitros pueden ser de derecho o de equidad. Los primeros deberán observar las disposiciones de derecho en la fundamentación de los laudos. Los segundos procederán con entera libertad, según sea más conveniente al interés de las partes, atendiendo principalmente a la equidad. Si no hubiere indicación de las partes sobre el carácter de los árbitros se entenderá que decidirán como árbitros de derecho. Los árbitros tendrán siempre en cuenta las estipulaciones del contrato y los usos y costumbres mercantiles".

io i Véase Baumeister Toledo, Algunas consideraciones, cit., p. 55: "inclusive el pronunciamiento en equidad exige y requiere que los árbitros o el juez facultado para así decidir, expresen los motivos por los cuales establecen la norma que consideran aplicable al caso y aquéllos en los que sustentan la decisión que con fundamento a ella se dicta en ese caso concreto". ARrarte Arisnabarreta, A. M., Sobre el deber de motivación y su aplicación en los arbitraje de conciencia, The- 
que no se decide por mera intuición sino con base en un razonamiento concreto ${ }^{102}$ no obstante la "libertad". Con lo que no habría que confundir la motivación de derecho con la motivación en general que también debe mediar en un arbitraje de equidad, y que no se mide propiamente por la extensión de las palabras ${ }^{\mathrm{IO}}$. Esto sobre la base de que ningún órgano jurisdiccional está exonerado del deber de motivar sus decisiones ${ }^{104}$. Por lo que no pareciera que el artículo 8 de la Ley de Arbitraje Comercial releve de motivación al laudo de equidad, sino de "fundamentos de derecho". Decidir conforme a la equidad no exime de ofrecer una fundación con base en tal valor ${ }^{\mathrm{IO} 5}$. Con lo cual sería enteramente recomendable que en todo caso, al margen del tipo de arbitraje y de lo que dispongan las partes, aunque sea someramente, siempre se motive el respectivo laudo arbitral a los fines de garantizar el derecho a la defensa, que presenta carácter irrenunciable y constitucional.

mis n. ${ }^{\circ}$ 43, p. 68, disponible en: http://dialnet.unirioja.es/descarga/articulo/5 I o9793.pdf: "En el caso específico de los procesos arbitrales -más aún en los arbitrajes de conciencia- esta exigencia debe ser más rigurosa, toda vez que la potestad de resolver conflictos e incertidumbres ha sido conferida por las mismas partes, generando en el árbitro el deber ineludible de demostrar que responde a tal acto de confianza, y hasta de fe, de manera imparcial y justa, lo que se debe demostrar a través de la explicitación de un razonamiento correcto que además conlleve un análisis escrupuloso de lo que resulta razonable para el caso concreto".

io2 Arrarte Arisnabarreta, ob. cit., p. 68: "es imprescindible que el juzgador y específicamente el árbitro demuestre a los litigantes y especialmente a la sociedad, que su decisión no es producto de su mera intuición, sino de un razonamiento correcto [...] ésta es la única manera [de] que la solución de conflictos por cualquiera de los mecanismos previstos en nuestro sistema jurídico sean verdaderas herramientas que faciliten la convivencia social, y no terminen convirtiéndose en generadores $[s i c]$ de frustraciones que rebelan al sentido común y de justicia”.

io3 Véase Fernández Rozas, J. C., "Motivación del laudo arbitral en equidad (Sentencia del TSJ Galicia CP г. ${ }^{a}$ n. ${ }^{\circ}$ I 8/20 г 2, de 2 de mayo)", Arbitraje. Revista de Arbitraje Comercial y de Inversiones, viI (2), 20I3, 47 I, nota 7, disponible en: http://eprints.ucm.es/2538I/I/Deber\% 20de\% 20 motivaci\% $\mathrm{C}_{3} \% \mathrm{~B}_{3}$ n.pdf: "La motivación no tiene que ver con la extensión de los fundamentos de derecho [... por lo que] puede estar perfectamente motivada una decisión que se apoye en argumentaciones escuetas o concisas, y a la inversa. Doctrina que es aplicable al arbitraje de equidad, bien que con las necesarias adaptaciones, que se traducen en una mitigación del rigor de la fundamentación jurídica, ya que en estos casos el árbitro no tiene la obligación, necesariamente, de ofrecer razones jurídicas, fundadas en normas jurídicas, para basar su decisión”.

I04 Ibíd., 475: "la afirmación de que el laudo de equidad no precisa motivación cada vez ofrece una menor entidad. Como se ha indicado, la motivación es una garantía de respeto de los derechos fundamentales que debe presidir cualquier actuación procesal y no un mero instrumento de cortesía hacia las partes que han entablado el arbitraje; incluso se llega a sostener que requiere un mayor rigor en la modalidad de equidad que en el arbitraje de Derecho, que cuenta a su favor con el método de la subsunción. Al carecer el árbitro de equidad prima facie de un soporte legal en el que fundamentar su decisión, deberá esforzarse de que su decisión sea la que mejor se acomode a las circunstancias y con la equidad. Una cosa es que los árbitros estén eximidos de fundamentar jurídicamente su decisión (motivación jurídica) y otra muy distinta que esa exoneración se extienda a la obligación de dictar un laudo 'congruente', atendiendo a la propia esencia de sentido común que debe adornar al arbitraje, y 'debidamente motivado"”.

I05 Un laudo arbitral carente de motivación sería como una decisión arbitral decidida conforme a la suerte, o tal vez peor, pues las partes nunca podrán conocer el fundamento jurídico o de equidad que condujo a la sentencia arbitral. 


\section{B. La inmotivación como causa de nulidad del laudo arbitral}

Es requisito fundamental -del que no escapa un laudo arbitral- la motivación de la decisión. Esto por cuanto "el laudo es al proceso arbitral, lo que la sentencia al proceso ordinario" ${ }^{\circ 06}$. La decisión de los árbitros ha sido denominada "sentencia arbitral", y se ha señalado que la decisión que recae en el arbitraje es una decisión formalmente idéntica a la sentencia ${ }^{107}$. Y la sentencia ha de estar motivada a tenor del artículo 243, ordinal 4 del Código de Procedimiento Civil venezolano ${ }^{\mathrm{ro8}}$. Es elemental que quien decide, explique las razones de hecho y de derecho en que fundamenta su decisión. Entre los requisitos de una decisión jurisdiccional por imperativo constitucional se ubica la motivación a fin de evitar la arbitrarie$\mathrm{dad}^{\mathrm{r} 09}$. Y recordemos que el arbitraje constituye función jurisdiccional. Por lo que es imperativo de justicia que se indiquen los parámetros o elementos que sirvieron de base para la motivación del laudo arbitral. De hecho, pensamos que la inmotivación no solo sería subsumible en el citado literal c del artículo 44 de la Ley de Arbitraje Comercial, a saber, que el procedimiento no se ha ajustado a la ley, sino que adicionalmente se traduce en "indefensión" Iо dado el carácter definitivo o de cosa juzgada del laudo arbitral. De allí que sostener que la inmotivación no constituye causa de nulidad del laudo arbitral es desconocer que la taxatividad de las causales de nulidad (numerus clausus) no exime que las obvias violaciones procesales sean subsumidas en las taxativas causales de ley por vía de sana interpretación.

El laudo no puede prescindir de una mínima motivación jurídica para evitar una "incongruencia omisiva de tal calibre" que determine una vulneración evidente del derecho a la defensa, lo que refuerza aún más la argumentación tendente a decretar la nulidad del laudo. La ausencia de motivación puede suponer

io6 Amado, L. y Pérez Bracamonte, N., "Una alternativa no judicial para la ejecución del laudo en Venezuela", Comercio et Tributum, Universidad Rafael Belloso Chacín, vol. II, 2009, 52, disponible en: http://www.urbe.edu/publicaciones/comercium/pdf/vol-2/3-alternativa-no-judicialnathali-perez-y-lucy-amado.pdf

io7 Sacristán, ob. cit., p. 45; Villasmil Vera y Hernández Villalobos, ob. cit., p. 389 : el laudo es asimilable a la sentencia judicial, de allí su paralelismo, y se alude a "sentencia arbitral".

Io8 "Los motivos de hecho y de derecho de la decisión"; TsJ/scc, Sentencia 43 I del I6-7- I 5, disponible en: http://historico.tsj.gob.ve/decisiones/scc/julio/I 79562-RC.00043 I-I 67 I 5-20I 5-I 3-757. HTML

iog Franciskdvic Ingunza, B. A., La sentencia arbitraria por falta de motivación en los bechos y en el Derecho, disponible en: http:// www.derecho.usmp.edu.pe/.../LA_SENTENCIA_ARBITRARIA_POR_F Arrarte Arisnabarreta, ob. cit., p. 68: la motivación es garantía esencial del justiciable a fin de eliminar cualquier atisbo de arbitrariedad del juzgador en cualquier tipo de procesos, resultando imprescindible no sólo que los conflictos sean resueltos, sino que además se perciba que lo fueron de una manera racional, razonable y justa; esta es la única manera de que la solución de un caso concreto trascienda y genere paz social. Fernández Rozas, Motivación..., cit., p. 469: "la falta de motivación de las decisiones que resuelven un litigio conduce a la arbitrariedad".

i io Véase Guzmán Galindo, ob. cit., p. $3^{8}$. 
una violación de los principios rectores del procedimiento arbitral, en concreto, del derecho de defensa ${ }^{\text {II I }}$.

Y así, también en el derecho español constituye causa de nulidad del laudo arbitral: "Que el laudo sea contrario al orden público". Y se afirma, sin ánimo de exhaustividad, que contrarían el orden público: (i) la vulneración de los principios de audiencia, contradicción o igualdad; (ii) la ausencia de litisconsorcio pasivo cuando este fuere necesario, o (iii) "cuando el laudo carezca de motivación adecuada y suficiente" " I2. Siendo esta última -para Bermejo Reales-, al igual que la indefensión, apreciable de oficio por el tribunal ${ }^{113}$, aunque se indica que el recurso de nulidad solo puede resolverse por un motivo alegado por las partes ${ }^{\mathrm{II}}$, no obstante que el recurso de "revisión" eventualmente ha mediado de oficio en Venezuela. En todo caso, debería regir la prudencia en este sentido, y en todo evento medir la gravedad del asunto ${ }^{15}$. Recordemos pues que lo que descarta la doctrina venezolana a los efectos de nulidad del laudo arbitral son los errores in iudicando ${ }^{\mathrm{II} 6}$. Siendo que la inmotivación se ubica en los errores in procedendo.

Ante la hipótesis de que se considere que la causal prevista en el literal f del artículo 44 de la Ley de Arbitraje Comercial no incluye los errores in procedendo, como la inmotivación, sino las materias excluidas del arbitraje, en todo caso la motivación forma parte necesaria del procedimiento arbitral de conformidad con el artículo 30 de dicha ley especial, por lo que su infracción ciertamente es subsumible en el literal c del artículo 44, a saber, que "el procedimiento arbitral no se ha ajustado a esta ley”. Adicionalmente, la inmotivación también produce indefensión, pues mal puede pretenderse que una sentencia inmotivada no susceptible de apelación o casación quede definitivamente firme sin perjuicio del referido derecho a la defensa.

De tal suerte que pretender que la motivación no constituye requisito del laudo arbitral, especialmente cuando ni siquiera se exija una motivación exigua -lo cual también es objeto de discusión ${ }^{117}$-, sino que se pretenda omitir enteramente dar al justiciable los parámetros que permiten a los árbitros configurar su

i i I Fernández Rozas, Motivación..., cit., pp. 476 y 477.

i 2 Bermejo Reales, ob. cit., p. 7 .

I 3 ibíd., p. Io.

I 4 Véase Rodner, ob. cit., p. 836; Alva NaVarro, ob. cit., pp. 92 y 97.

I 5 Amezaga, B., ob. cit.

i 6 Véase supra: Mezgravis, Recursos..., cit., p. 244.

I 7 Lo cual genera una discusión todavía más álgida o compleja. Véase Zerpa, L. I., "La motivación de la sentencia. Criterios de la Sala de Casación Civil", Revista de Derecho Universidad Católica Andrés Bello n. ${ }^{\circ}$ 53, I 998, 2 I4, disponible en: http://www.ulpiano.org.ve/revistas/bases/artic/texto/RDUCAB/53/UCAB_I998_53_2 I6-I89.pdf: deben revisarse los criterios tradicionales relativos a una motivación escasa o exigua en beneficio del derecho a la defensa y su indiscutible carácter de riguroso orden público. León PAStor, R., ¿Los defectos de motivación justifican la anulación del laudo? Una revisión crítica de los recursos de anulación de laudo presentados ante la Corte de Lima en el año 2013, abril, 2014, disponible en: http://lexarbitri.pe/wp-content/uploads/2014/o7/Los- 
decisión, constituye una franca violación de la tutela judicial efectiva, del debido proceso y del derecho a la defensa. La inmotivación (y la arbitrariedad e ilegalidad que en ella subyace) no se compadece con las formalidades procesales que el procedimiento arbitral reclama. Acudir a un medio alternativo de justicia no puede suponer el sacrificio de formalidades esenciales comunes a todo proceso. Por lo que se trata de un vicio que afecta de nulidad el laudo arbitral, más allá inclusive de tales literales por tratarse de una formalidad esencial e imperativa.

$\mathrm{Y}$ es que "el arbitraje como medio alternativo de justicia no es contrario al principio-garantía constitucional del debido proceso" ${ }^{18}$. Dentro de las garantías constitucionales cabe destacar el derecho a la defensa, el derecho de acceso a las pruebas $^{119}$, así como formalidades obligatorias, por ejemplo, la "motivación" ${ }^{20}$.

Se ha señalado acertadamente que "el origen y la legitimidad del arbitraje, se encuentra en la autonomía de la voluntad, la misma que está limitada y se ejerce conforme a la Constitución y a los derechos fundamentales" ${ }^{2}$ I. Entre los que cabe referir aquellos que constituyen el núcleo del debido proceso arbitral ( $\sin$ los cuales no existiría debido proceso de ninguna naturaleza): - el derecho de defensa, que se manifiesta en la contradicción y audiencia; - el derecho a un juez (o árbitro) imparcial; - el derecho a la prueba (que comprende el derecho al ofrecimiento, admisión y valoración de medios de prueba); - el derecho a una debida motivación de las decisiones; - el derecho a la igualdad de trato ${ }^{\text {I22 }}$.

Por lo que la motivación es requisito esencial del laudo para fines de su conformidad con el derecho -según indicamos, inclusive irrenunciable no obstante el artículo 30 LAC-. Deben los árbitros dar las razones jurídicas que fundamentan su decisión. En tal sentido, ha referido la jurisprudencia, por ejemplo, que la motivación del daño moral en cuanto a la indicación de los parámetros que permiten estimarlo constituye parte de la tutela judicial efectiva consagrada en la Carta Política, pues lo contrario configura inmotivación ${ }^{\mathrm{I} 23}$. De tal suerte que también con tales parámetros de motivación deberá cumplir el laudo arbitral, pues lo contrario sería una forma de evadir las debidas garantías procesales mediante la vía del arbitraje. Siendo esto ajeno enteramente al sentido que pretende el orden jurídico con dicho medio alternativo de resolución de controversias.

errores-de-motivacion-en-los-laudos-arbitrales-RLP.pdf; TsJ//scs, Sentencia 288 de I6-5-02, disponible en: http://historico.tsj.gob.ve/decisiones/scs/mayo/RC288-I60502-0 I635.HTM

i 8 Duque Corredor, R., Temario de derecho constitucional y de derecho público, Bogotá, Legis, 2008, p. 277.

I 19 Ibíd., p. 279.

I 20 Ibíd., p. 28I, resaltado fuera de texto.

i 2 Arrarte Arisnabarreta, A. M., Apuntes sobre el debido proceso en el arbitraje: la anulación del laudo y el proceso de amparo, 3 , disponible en: http:// www.justiciayderecho.org/revista I/articulos/anamariaarrarte.pdf

I 22 Ibíd., p. 24, resaltado fuera de texto.

I 23 TSJ/scc, Sentencia OOOIO5 del 2 I-4-IO. 
Ciertamente, además de la inmotivación, diversas podrán ser las violaciones a la defensa que eventualmente pudieran presentarse en un juicio arbitral. No es nuestro objetivo enumerarlas porque ellas quedarán a la apreciación del juzgador a la luz del caso concreto. Pero lo que hemos querido significar con estas breves notas es que mal puede el justiciable acudir al procedimiento arbitral para verse disminuido en las garantías procesales que son imperativas en cualquier modalidad del sistema de justicia. El ciudadano no puede ver limitados sus derechos procesales constitucionales ante la justicia privada porque esta perdería el sentido que el constituyente pretendió concederle en el artículo $25^{8}$ de la Carta Política.

De allí que acertadamente se afirme: "No se trata de enfrentar arbitraje y Constitución, sino de defender ambos. Y es así, porque sólo salvaguardada la Constitución puede salvaguardarse el régimen de libertades en el que entronca el arbitraje" ${ }^{24}$.

\section{A manera de conclusión}

El procedimiento arbitral como mecanismo de justicia alternativo debe respetar las garantías jurisdiccionales, entre las que cabe considerar el derecho a la defensa. En la generalidad de las legislaciones, incluyendo la venezolana, se consagra la indefensión como causa de nulidad del laudo arbitral. La necesidad de motivación del laudo arbitral como proyección de lo anterior es extensible inclusive al arbitraje de equidad. Por lo que cabe concluir que no cabe indefensión en el procedimiento arbitral, so pena de verse el respectivo laudo viciado de nulidad. El arbitraje mal puede traducirse en una reducción de los derechos procesales del justiciable.

\section{Bibliografía}

Aarons P., F., "Los medios alternativos de solución de controversias y las transacciones financieras", en Memoria Arbitral, coord. C. Milagros Betancourt, Caracas, Centro Empresarial de Conciliación y Arbitraje (CEDCA), 20 I I.

Alva Navarro, E., Arbitraje. La anulación del laudo. Primera Parte, con la colaboración de Roger Vidal Ramos, Perú, Biblioteca de Arbitraje del Estudio Mario Castillo Freyre, 20 I I, disponible en: http://www.castillofreyre.com/ archivos/pdfs/vol I4.pdf

I 24 Véase Andaluz Vegacenteno, H., "Argumentación, arbitraje y arbitrariedad: las contradicciones del Tribunal Constitucional en el recurso directo de nulidad contra laudos", Iuris Tantum. Revista Boliviana de Derecho n. ${ }^{\circ}$ i9, Santa Cruz de la Sierra, enero 2015, disponible en: http:// www.scielo.org.bo/scielo.php?pid=S2070-8 I 5720 I 5000 I $00004 \&$ script=sci_arttext 
Álvarez Alberto, T., Procesos civiles especiales contenciosos, 4. ${ }^{a}$ ed., Caracas, Universidad Católica Andrés Bello, 20 I 2, t. I.

Amado, L. y Pérez Bracamonte, N., "Una alternativa no judicial para la ejecución del laudo en Venezuela", Comercio et Tributum, Universidad Rafael Belloso Chacín, vol. II, n. ${ }^{\circ}$ I, 2009, disponible en: http://www.urbe.edu/publicaciones/comercium/pdf/vol-2/3-alternativa-no-judicial-nathali-perezy-lucy-amado.pdf

Amezaga, B., La anulación de los laudos arbitrales en Francia. Furisprudencia reciente, disponible en: www.ohadac.com/.../anulacion-de-laudo-en-francia.amezaga-bingen.pdf

Anzola, J. E., "El fatigoso camino que transita el arbitraje", en Arbitraje comercial interno e internacional. Reflexiones teóricas y experiencias prácticas, coord. Irene de Valera, Caracas, Academia de Ciencias Políticas y Sociales y Comité Venezolano de Arbitraje, Serie Eventos I8, Caracas, 2005.

Araque Benzo, L. A., Manual de Arbitraje Comercial, Caracas, Jurídica Venezolana y Araque Reyna Sosa Viso \& Asociados, 20 I I.

Arrarte Arisnabarreta, A. M., "Sobre el deber de motivación y su aplicación en los arbitrajes de conciencia”, Themis n. ${ }^{\circ}$, disponible en: http://dialnet. unirioja.es/descarga/articulo/5 I09793.pdf

Arrarte Arisnabarreta, A. M., Apuntes sobre el debido proceso en el arbitraje: la anulación del laudo y el proceso de amparo, http:// www.justiciayderecho.org/ revista I/articulos/anamariaarrarte.pdf

Asapchi, M., Arbitraje comercial: impugnación y ejecución del laudo arbitral, Caracas, Universidad Católica Andrés Bello, Dirección General de Estudios de Postgrado, Especialización en Derecho Mercantil, 2007, http://w2.ucab.edu.ve/ tesis-digitalizadas2/ths_grade/especializacion-de-derecho-mercantil.html

Aveledo Morasso, L. E., "El recurso de nulidad en el arbitraje civil y comercial", en Revista de la Fundación Procuraduría General de la República n. ${ }^{\circ} 2$ I, año I3, I999.

Barnola Quintero, J. P., "Reconocimiento y ejecución del laudo arbitral comercial en Venezuela", en Revista Venezolana de Estudios de Derecho Procesal n. ${ }^{\circ}$ I, Instituto Venezolano de Estudios de Derecho Procesal, Invedepro, Livrosca, enero-junio I999. 
Barragán Arango, L. A., "El laudo arbitral”, en El contrato de arbitraje, Eduardo Silva Romero (dir. académico) y Fabricio Mantilla Espinosa (coord. académico), Bogotá, Legis y Universidad del Rosario, 2005.

Baumeister Toledo, A., "Algunos tópicos sobre el procedimiento en la ley de Arbitraje Comercial”, en Arbitraje comercial interno e internacional. Reflexiones teóricas y experiencias prácticas, coord. Irene de Valera, Caracas, Academia de Ciencias Políticas y Sociales y Comité Venezolano de Arbitraje, Serie Eventos I8, Caracas, 2005 .

Baumeister Toledo, A., "Algunas consideraciones sobre el procedimiento arbitral en la nueva Ley de Arbitraje Comercial”, Revista Venezolana de Estudios de Derecho Procesal n. ${ }^{\circ}$ I, Instituto Venezolano de Estudios de Derecho Procesal, INVEDEPRo, Livrosca, enero-junio, I999.

Badell Madrid, R., "El recurso de revisión constitucional en el arbitraje", Revista Comité de Arbitraje 2010-20I I, http://www.cedca.org.ve/sites/default/ files/Revista\% 2ode\% 20Arbitraje\% 202 da\% 20Edici\% $\mathrm{C}_{3} \% \mathrm{~B}_{3}$ n.pdf

Badell Madrid, R. et al., "Comentarios a la Ley de Arbitraje Comercial”. Cuadernos furídicos Badell \& Grau. Caracas, 1998.

Benaín Izaguri, S., "Reflexiones sobre las posibilidades probatorias de los Centros de Arbitraje", en Revista Venezolana de Estudios de Derecho Procesal n. ${ }^{\circ}$, Instituto Venezolano de Estudios de Derecho Procesal, Invedepro, Livrosca, enero-junio I999.

Bermejo Reales, L. F., "La eficacia de las decisiones arbitrales: la impugnación y ejecución de los laudos", Revista furídica de Castilla y León n. ${ }^{\circ}$ 29, enero 2013, http://dialnet.unirioja.es/servlet/articulo? codigo $=4225303$ \&orden

Bonnemaison W., J. L., Sobre la naturaleza y el objeto del arbitraje, disponible en: http://servicio.bc.uc.edu.ve/derecho/revista/57/57-20.pdf

Caridad de Navarro, M., "Arbitraje comercial: Nuevo paradigma para la administración de justicia", Frónesis, vol. I2, n. ${ }^{\circ} 2$, Caracas, Agosto 2005, http:// www.scielo.org.ve/scielo.php?pid=S I 3 1 5-62682005000200005\&script=sci_ arttext

Caridad de Navarro, M., Contradicciones e imprecisiones legales de la institución arbitral en Venezuela, trabajo especial para ascender a la categoría de asociado, Maracaibo, Universidad del Zulia, Facultad de Ciencias Jurídicas y Po- 
líticas, junio 2006, http://tesis.luz.edu.ve/tb_acen_inv/tde_busca/arquivo. php? $\operatorname{codArquivo=27}$

Coronel Jones, C., Arbitraje y procedimiento en Ecuador, http://www.latinarbitrationlaw.com/arbitraje-y-procedimiento-en-ecuador/

Criollo Mayorga, G., Problemas de la "acción” de nulidad del laudo arbitral, disponible en: http://www.cejamericas.org

De Jesús O., A., "Validez y eficacia del acuerdo de arbitraje en el Derecho Venezolano", en Arbitraje comercial interno e internacional. Reflexiones teóricas y experiencias prácticas, coord. Irene de Valera, Caracas, Academia de Ciencias Políticas y Sociales y Comité Venezolano de Arbitraje, Serie Eventos i8, Caracas, 2005 .

De Jesús O., A., “Crónica de Arbitraje Comercial n. ${ }^{\circ}$ ”, Revista de Derecho n. ${ }^{\circ} 23$, Tribunal Supremo de Justicia, 2006.

De Jesús O., A., "La Sala Constitucional y el arbitraje comercial. Hacia un régimen racional de control judicial del laudo arbitral en el Derecho Venezolano", Revista Peruana de Arbitraje 3, Editora Jurídica Grijley, 2006, disponible en: phttp://www.peruarbitraje.org/pdf/revista/REVISTA_PERUANA_DE_ARBITRAJE_RPA_3_2006.pdf

Delgado Soto, G., Nulidad de la cláusula arbitral, Arbitraje comercial interno e internacional. Reflexiones teóricas y experiencias prácticas, coord. Irene de Valera, Caracas, Academia de Ciencias Políticas y Sociales y Comité Venezolano de Arbitraje, Serie Eventos I 8, 2005.

De Maekelt, T. B. y Madrid, C., "Al rescate del arbitraje en Venezuela”, en El derecho privado y procesal en Venezuela Homenaje a Gustavo Planchart Manrique, Caracas, Universidad Católica Andrés Bello/Tinoco, Travieso, Planchart \& Núñez, Abogados, 2003, t. II.

Díaz-Candia, H., El correcto funcionamiento expansivo del arbitraje (Teoría general del arbitraje), 2. ${ }^{\mathrm{a}}$ ed., Caracas, Legis, 2013.

Díaz-Candia, H., "La conciliación y el arbitraje comercial en el contexto de la reciente jurisprudencia del Tribunal Supremo de Justicia de la República Bolivariana de Venezuela", Memoria Arbitral, coord. C. Milagros Betancourt, Caracas, Centro Empresarial de Conciliación y Arbitraje (CEDCA), 20 I I. 
Domínguez Guillén, M. C., Ensayos sobre Capacidad y otros temas de Derecho Civil, $3 .^{a}$ ed., Caracas, Tribunal Supremo de Justicia, Colección Nuevos Autores n. ${ }^{\circ}$ I, 2010.

Duque Corredor, R., Temario de Derecho Constitucional y de Derecho Público, Bogotá, Legis, 2008.

Fernández Rozas, J. C., La Constitución mexicana y el arbitraje comercial. Cuest. Const. n. ${ }^{\circ}$ I6 México ene./jun. 2007, disponible en: http://www.scielo.org.mx/scielo. php?pid=SI405-9I932007000 I00006\&script=sci_arttext

Fernández Rozas, J. C., "Motivación del laudo arbitral en equidad (Sentencia del tsj Galicia CP r. ${ }^{a}, \mathrm{n}^{\circ}$ i 8/20 2 , de 2 de mayo)". Arbitraje. Revista de Arbitraje Comercial y de Inversiones, vII (2), 20I3, disponible en: phttp://eprints. ucm.es/2 538 I/I/Deber\% 2ode\% 2omotivaci\% C3\%B3n.pdf

Franciskdvic Ingunza, B. A., La sentencia arbitraria por falta de motivación en los bechos y en el Derecho, disponible en: http:// www.derecho.usmp.edu.pe/.../ LA_SENTENCIA_ARBITRARIA_POR_F

Fortún, A. y Álvarez-Garcillán, G., La impugnación de los laudos arbitrales, disponible en: http://www.cuatrecasas.com/media_repository/docs/esp/la_ impugnacion_de_los_laudos_arbitrales._economist_jurist,_n_I 7 I_2OI 3_ (junio)_340.pdfLa

Gabaldón M., F., Análisis a la Ley de Arbitraje Comercial, Caracas, Livrosca, C.A., I999.

Gabaldón M., F., “Algunas temas en torno a la Ley de Arbitraje Comercial”, en Estudios de Derecho Procesal Civil, Libro Homenaje a Humberto Cuenca, Colección Libros Homenaje n. ${ }^{\circ}$ 6, Caracas, Tribunal Supremo de Justicia, 2002.

Gómez-Palacio, I., El laudo arbitral no motivado. Vía de solución poco explorada en México, http://www.biblio.juridicas.unam.mx/libros/6/2552/r6.pdf

González Arteaga, J.: "Recursos interponibles contra el laudo arbitral a la luz de la ley de arbitraje comercial", Revista Venezolana de Estudios de Derecho Procesal n. ${ }^{\circ}$ I, Instituto Venezolano de Estudios de Derecho Procesal, InveDEPRo, Livrosca, enero-junio I999.

González Carvajal, J. I., "Reflexiones sobre las tendencias jurisprudenciales sobre conflicto de 'jurisdicción' cuando existe acuerdo de sometimiento ar- 
bitral", Revista Venezolana de Legislación y Furisprudencia n. ${ }^{\circ}$ 4, 2014, http:// www.rvlj.com.ve

Guzmán Galindo, J. C., "La falta de motivación del laudo como causal de anulación en la ley de arbitraje peruana", Arbitraje PUCP, disponible en: http:// revistas.pucp.edu.pe/index.php/arbitrajepucp/article/download/.../980o

Haderspock, B., Intentos fallidos de inconstitucionalizar el arbitraje como proceso de única instancia, Bolivia, Legis, disponible en: http://www.arbitrajecomercial. com/BancoConocimiento/J/jurisprudencia_dr_haderspoock/jurisprudencia_dr_haderspoock.asp?CodSeccion= $=$ I 5

Hernández Machado, E., La inmutabilidad del proceso arbitral, disponible en: http://eldia.com.do/la-inmutabilidad-del-proceso-arbitral/

Henríquez La Roche, R., El Arbitraje Comercial en Venezuela. Venezuela, Centro de Arbitraje de la Cámara de Comercio de Caracas, 2000.

Hernández-Bretón, E., Arbitraje y Constitución: El arbitraje como derecho fundamental, Arbitraje comercial interno e internacional. Reflexiones teóricas y experiencias prácticas, coord. Irene de Valera, Caracas, Academia de Ciencias Políticas y Sociales y Comité Venezolano de Arbitraje, Serie Eventos I 8, 2005.

Hernández-Bretón, E., "El arbitraje y las normas constitucionales en Venezuela: lo malo, lo feo y lo bueno", Boletín de la Academia de Ciencias Políticas y Sociales n. ${ }^{\circ}$ I 49, julio-diciembre, 2010 , disponible en: http://acienpol.msinfo. info/bases/biblo/texto/boletin/2oro/BolacPs_20IO_I49_389-407.pdf

Hernández Mendible, V., "La inconsistencia argumentativa en el análisis del Derecho a la defensa", Revista Tachirense de Derecho n. ${ }^{\circ}{ }^{2} 3$, enero-diciembre 2001.

Herrera Mercado, H., El arbitraje en el Derecho privado, Los contratos en el Derecho Privado, dirs. académicos Fabricio Mantilla y Francisco Ternera. Bogotá, Legis/Universidad del Rosario, 2008.

Hung Vaillant, F., "Principios orientadores del arbitraje en la ley de arbitraje comercial y los recursos contra el laudo arbitral”, xxvi Jornadas J. M. Domínguez Escovar: Los medios alternativos de resolución de conflictos. 3 al 7 enero de 200 I, Instituto de Estudios Jurídicos del Estado Lara; Colegio de Abogados del Estado Lara, Barquisimeto, 200 I. 
Hung Vaillant, F., "Apostillas a cinco sentencias en materia arbitral dictadas por el Tribunal Supremo de Justicia", en El derecho privado y procesal en Venezuela, Homenaje a Gustavo Planchart Manrique, Caracas, Universidad Católica Andrés Bello/Tinoco, Travieso, Planchart \& Núñez, Abogados, 2003, t. II.

León Feoli, A., Debido proceso como causal de nulidad del laudo arbitral, análisis de precedentes de la Sala Primera de la Corte Suprema de fusticia, disponible en: http://sitios.poder-judicial.go.cr/sala I/Temas\% 2 ojurisprudenciales/Arbitrajes-debido\% zoproceso.pdf

León Pastor, R., ¿Los defectos de motivación justifican la anulación del laudo? Una revisión crítica de los recursos de anulación de laudo presentados ante la Corte de Lima en el año 2013, abril 2014, http://lexarbitri.pe/wp-content/uploads/2014/o7/ Los-errores-de-motivacion-en-los-laudos-arbitrales-RLP.pdf

Mantellini González, P.J.,Elarbitramento y el arbitraje comercial, Boletín de la Academia de Ciencias Politicas y Sociales n. ${ }^{\circ}$ 42, I 986, disponible en: http://acienpol. msinfo.info/bases/biblo/texto/boletin/I986/BolacPs_i986_42_I05_IO6_ I73-I93.pdf

Martín BraÑas, C., "La acción de anulación frente a laudos arbitrales: especial referencia a su tramitación procedimental", Foro, nueva época, 3-2006, pp. II3-I 56, disponible en: https://revistas.ucm.es/index.php/Foro/article/ download/.../13649

Martínez Manotas, P., "Algunas consideraciones sobre la cláusula arbitral desde la legislación colombiana y mexicana", tesis para obtener el grado de maestro en Derecho de los negocios internacionales, Universidad Iberoamericana, México, 2007, disponible en: http://www.bib.uia.mx/tesis/pdf/or $4847 /$ oI $4847 . p d f$

Mejía Arnal, L.A., "El arbitraje: visión histórica y de Derecho Comparado", Revista Venezolana de Estudios de Derecho Procesal n. ${ }^{\circ}$ I, Instituto Venezolano de Estudios de Derecho Procesal, invedepro, Livrosca, enero-junio, I999.

Mezgravis, A., Recursos contra el laudo arbitral comercial, La Ley de Arbitraje Comercial, Caracas, Biblioteca de la Academia de Ciencias Políticas y Sociales, Serie Eventos n. ${ }^{\circ}$ 13, I 999.

Mezgravis, A., "El amparo constitucional y el arbitraje", Revista de Derecho Administrativo n. ${ }^{\circ}$ 6, mayo-agosto, I 999. 
Mogollón Rojas, I. D., El Arbitraje Comercial Venezolano, Caracas, Vadell Hermanos Editores, 2004 .

Monroy Cabra, M. G., Recursos contra el laudo arbitral, El contrato de arbitraje, Eduardo Silva Romero (dir. académico) y Fabricio Mantilla Espinosa (coord. académico), Bogotá, Legis/ Universidad del Rosario, 2005.

Nava González, J. G., "El arbitraje comercial y el derecho fundamental de la tutela judicial efectiva”, Boletín de Investigación y Postgrado, Decimosexta edición, Universidad Privada Dr. Rafael Belloso Chacín, disponible en: http:// www I r .urbe.edu/boletines/postgrado/? p $=762$

Oppetit, B., Teoría del arbitraje, Bogotá, Legis, 2006.

Ortiz Herbener, A., "Acción de nulidad de laudos arbitrales en el Derecho Procesal ecuatoriano", Revista furídica, Facultad de Derecho, Universidad Católica de Guayaquil, disponible en: www.revistajuridicaonline.com

Parodi, G., "La cláusula arbitral: Efectos de la elección de la sede del arbitraje y el control judicial. Hacia un sistema de congruencias", Revista de Derecho de la Universidad de Montevideo n. ${ }^{\circ}$, año II, 2003, http://revistadercho.um.edu.uy

Petit Guerra, L., "Breves reflexiones sobre sentencias en materia arbitral”, Revista Venezolana de Estudios de Derecho Procesal n. ${ }^{\circ}$ I, Instituto Venezolano de Estudios de Derecho Procesal, invedepro, Livrosca, enero-junio i999.

Petit Guerra, L., El sistema de pruebas en el arbitraje desde la asunción del debido proceso como derecho fundamental, disponible en: http://www.cedca.org.ve/documentos/Luis-Petit.pdf

Petsold-Rodríguez, M., "Algunas consideraciones sobre el arbitraje en general", Derecho y Sociedad n. ${ }^{\circ} 4,2003$, Revista de estudiantes de Derecho de la Universidad Monteávila, disponible en: http://www.ulpiano.org.ve/revistas/ bases/artic/texto/DERYso/4/deryso_2003_4_27-40.pdf

Petsold-Rodríguez, M., "Algunas consideraciones sobre el acuerdo arbitral en la Ley de arbitraje comercial, y la cláusula arbitral y el compromiso arbitral en el Código de Procedimiento Civil de Venezuela”, en Estudios de derecho procesal civil, Libro Homenaje a Humberto Cuenca, Colección Libros Homenaje n. ${ }^{\circ}$ 6, Caracas, Tribunal Supremo de Justicia, 2002. 
Reggiardo, M., Las causales de anulación del laudo en el Perú, disponible en: http://lexarbitri.pe/wp-content/uploads/2014/o3/Las-causales-deanulaci\% $\mathrm{C}_{3} \% \mathrm{~B}_{3}$ n-de-laudo-I 5.2.I4-Mario-Reggiardo.pdf

Remón, J., La anulación del laudo: el pacto de exclusión y el orden público, disponible en: http://www.uria.com/documentos/publicaciones/rgoo/documento/ o6 IlaudoUM.pdf?id= 1942

Rengel-Romberg, A., Naturaleza jurisdiccional del laudo arbitral, Arbitraje comercial interno e internacional. Reflexiones teóricas y experiencias prácticas, coord. Irene de Valera, Caracas, Academia de Ciencias Políticas y Sociales/Comité Venezolano de Arbitraje, Serie Eventos n. ${ }^{\circ}$ I 8, 2005.

Rodner, J. O., "La anulación del laudo arbitral", en Estudios de derecho procesal civil, Libro Homenaje a Humberto Cuenca, Colección Libros Homenaje n. ${ }^{\circ}$ 6. Caracas, Tribunal Supremo de Justicia, 2002.

Sacristán, E. B., "Control constitucional en el Arbitraje", Revista Bresileira de Infraestrutura RBINF, año 3, n. ${ }^{\circ}$ 5, junio, Janeiro, Fórum, 2014.

SAGHY, P., "La convención de arbitraje: por el avance de la justicia estatal frente al arbitraje comercial", Revista de la Facultad de Ciencias Furídicas y Políticas n. ${ }^{\circ}$ I 29, Universidad Central de Venezuela, 2007.

SAghy Cadenas, P., La renuncia tácita al arbitraje, junio de 201 5, disponible en: http:// www.cedca.org.ve/sites/default/files/La \% 2 orenuncia \% 2ot\% $\mathrm{C}_{3} \%$ Aı cita \% 20 al\% 2oarbitraje\% 20-Pedro\% 2oSaghy.pdf

Sarmiento Sosa, C. J., Ley de Arbitraje Comercial, Caracas, Livrosca, I999.

Talero Rueda, S., "Reflexiones sobre la revisión judicial de fondo de los laudos arbitrales", Lima Arbitration n. ${ }^{\circ}$ 3, 2008/2009, disponible en: http://limaarbitration.net/LAR3-4/Santiago-Talero-Rueda.pdf

Véronique Schlaepfer, A. y Cremades, A.-C., La motivación de los laudos en arbitraje comercial internacional y en arbitraje de inversión, Arbitraje internacional, pasado, presente y futuro. Libro Homenaje a Bernardo Cremades e Yves Derains, coords. Carlos Alberto Soto Coaguila y Delia Revoredo Marsano de Mur. Lima, Instituto Peruanos de Arbitraje, 20 13, t. II, disponible en: http://www. swlegal.ch/cmspages/GetFile.aspx? disposition=attachment 
Vidal Ramírez, F., "Jurisdiccionalidad del arbitraje”, Revista peruana de arbitraje 3, Grijley, 2006, disponible en: http://www.peruarbitraje.org/pdf/revista/REVISTA_PERUANA_DE_ARBITRAJE_RPA_3_2006.pdf

Villasmil Vera, Y. C. y Hernández Villalobos, L. L., "Régimen legal del arbitraje comercial independiente en Venezuela", Revista de Derecho n. ${ }^{\circ}$ I 4 , Caracas, Tribunal Supremo de Justicia, 2004.

Zerpa, L. I., "La motivación de la sentencia. Criterios de la Sala de Casación Civil", Revista de Derecho Universidad Católica Andrés Bello n. ${ }^{\circ}$ 53, I998, disponible en: http://www.ulpiano.org.ve/revistas/bases/artic/texto/RDUCAB/53/ UCAB_I998_53_2 I6-I89.pdf

Zumbiehl, F. y Anzola, J. E., El Tribunal Supremo de Venezuela riñe con el Arbitraje, pp. $3^{8}$ y 39, disponible en: http://eanzola.com/images/uploads/44-El_TSJ_ ri\% $3 \%$ B re_con_el_arbitraje-Final.pdf 